$$
\begin{aligned}
& \text { جامعـة المنصــورة } \\
& \text { كليـــة النربية }
\end{aligned}
$$

أثر البديل "جميع ها سبق" على الخصائص السيكومترية$$
\text { للاختبار التصصيلي ذي الاختيار هن هتعدد }
$$

$$
\begin{aligned}
& \text { إعداد } \\
& \text { د. بندر بن زيد سالم الأمير } \\
& \text { الإدارة العامة للتعليم بنطقة مكة المكرمة }
\end{aligned}
$$

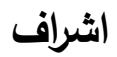

$$
\begin{aligned}
& \text { د/ عبد الله عبد الغنى صبرفى } \\
& \text { مجــلة كلـــية التربية - جامعـــة المنصــــورة }
\end{aligned}
$$

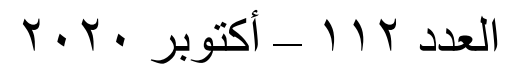




\section{أثر البديل "جميع ما سبق" على الخصائص السيكومترية للاختبار التحصيلي ذي الاختيار من متعدد الخدي من من}

\section{د. بندر بن زيد سـالم الأمير}

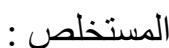

هدفت الدراسة إلى الكثف عن أثر استخدام البديل "جميع ما سبق" على الخصائص السيكومترية

(الصدق والثبات) لاختبار تحصيلي من نوع اختيار من متعدد في مادة الرياضيات وعلى خصائص فقراته

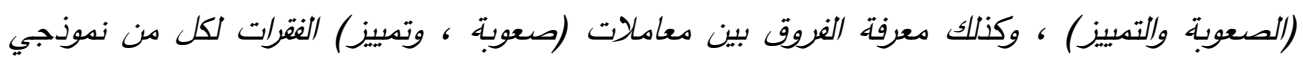

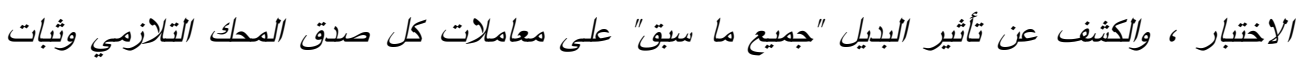

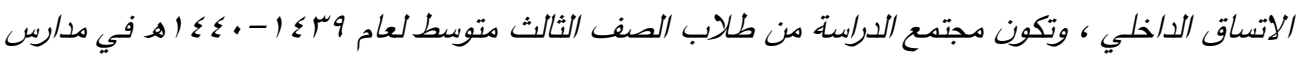

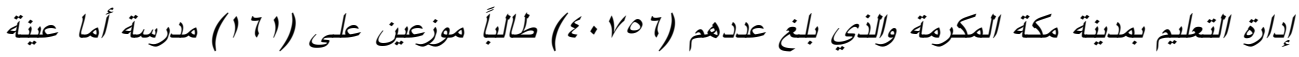

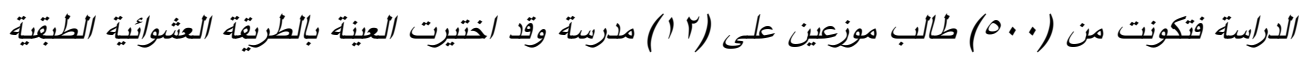

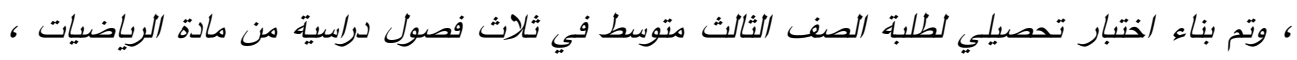

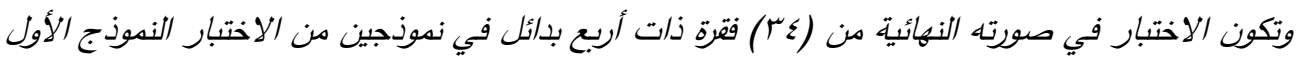

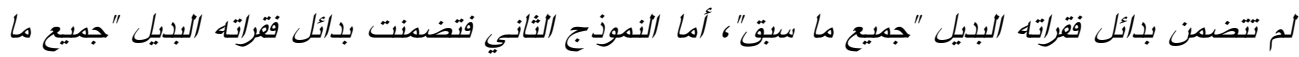

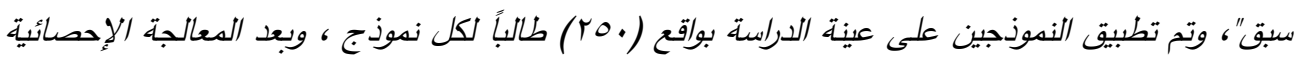

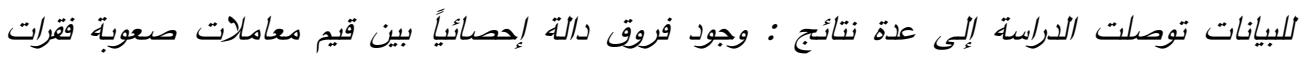

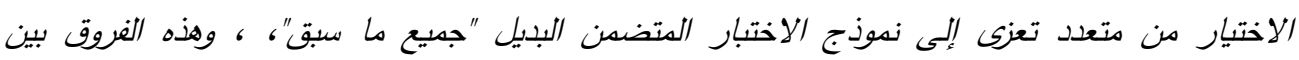

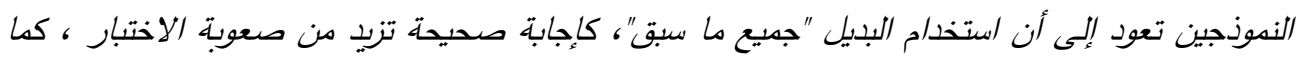

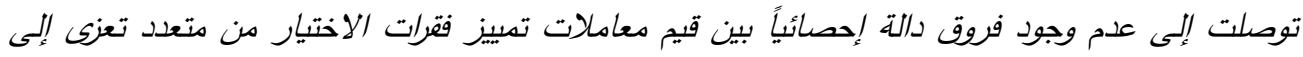

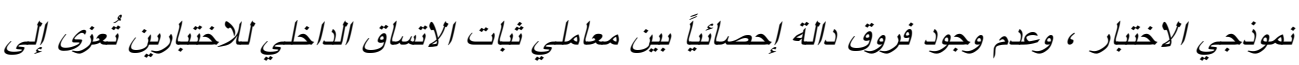

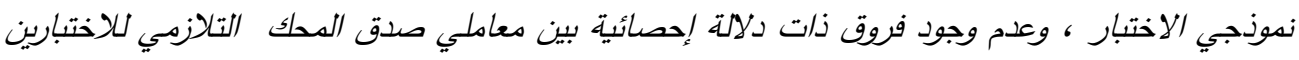

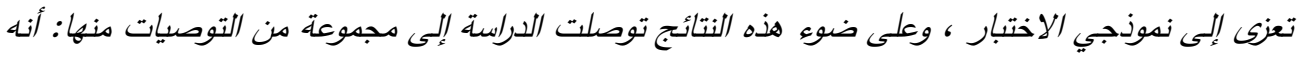

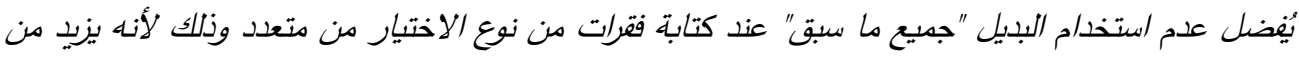

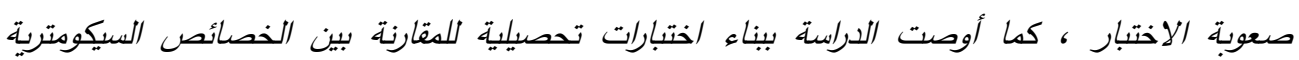

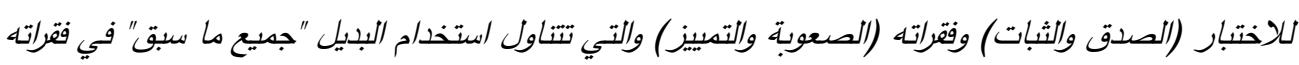
لمواد أخرى ولدى مراحل تعليمية مختلفة. الكلمات الهفتاحية : جميع ما سبق ، الخصائص السيكومترية ، الاختبار التحصيلي ذي الاختيار من متعدد ، معامل الصعوبة ، دعامل التمييز

\section{Abstract}

$r \wedge \cdot \odot$ 
The aim of this study was to investigate the effect of the use of the alternative "All the above" on the characteristics of the psychometric (Validity and Reliability) to the multiple-choice achievement test in the field of Mathematics and the characteristics of its items (difficulty and discrimination) and also distinguish the differences of both test models, as well to detecting the effect of the alternative "All the above" on the indexes of both stability of internal consistency and the validity of the collaterally test. The study population consisted of intermediate students in the third grade (1439/ 1440) in the schools of the Education Administration in Makkah city which their number reached (40756) students distributed over(161) school. The sample of the study consisted of (500) students distributed over (12) schools. The sample was selected by the random stratified method. Achievement test was constructed for the third grade intermediate students in three semesters of mathematics. The final test consisted of (34) item of four alternatives in two models of the test. The first model did not include alternatives of its alternative paragraphs "All the above", but the second model included alternatives of its alternative paragraphs "All the above". The two models were applied to a sample of study with (250) students per model. After statistical analysis treatment of the data, the results of the study were as follows : There are statistically significant differences between the indexes of the difficulty of multiple choice items due to the test model which include the alternative "All the above". And there are no statistically significant differences between the Discrimination indexes of the multiple-choice items attributed to the two test models. And there are no statistically significant differences between the two indexes of the Reliability of internal consistency for both tests attributed to the two test models. And there are no statistically significant differences between the two indexes of the validity of the collaterality test for both tests attributed to the two test models. On the basis of these results, this study came out with a set of recommendations, including: Prefer not to use when writing items of multiple choice type because it makes the test more difficult. Constructing diagnostic tests to compare the psychometric characteristics of the test (Validity and Reliability) and its items (difficulty and discrimination), which deal with the use of the achievment "All the above" in the multiple choice paragraphs of other materials.

Keywords : "All the above", Psychometric Characteristics, Multiple-choice achievment Test 
تعتبرالاختبارات التحصيلية من أهم وسائل التقويم التي يستخدمها المعلمون في المدارس

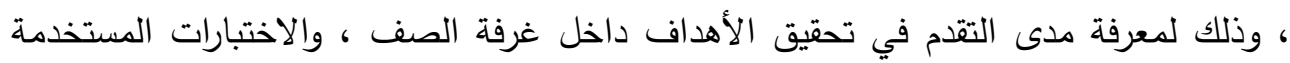

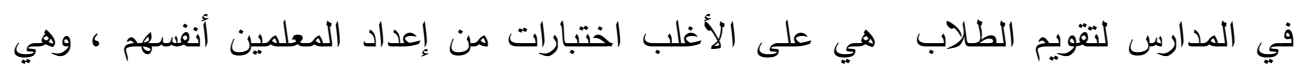

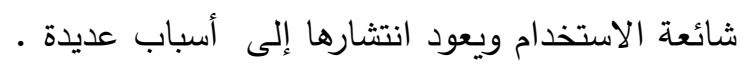
وقد ذكر كاري(Carey,1994) بعضاً من هذه الأسباب: منها أن المعلم يستطيع

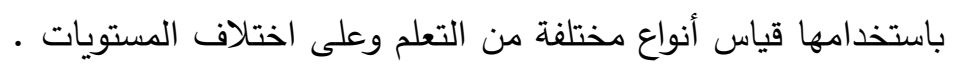

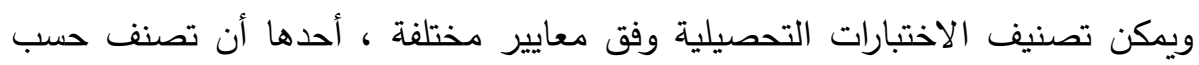
طبيعة الإجابة المطلوبة فتصنف إلى: الاختبارات ذات الإجابة المصاغة والاختبارات ذات الإجابة المنتقاة ـ ويتوقف استخدام هذه الأنواع من الفقرات على مجموعة من العوامل منها :

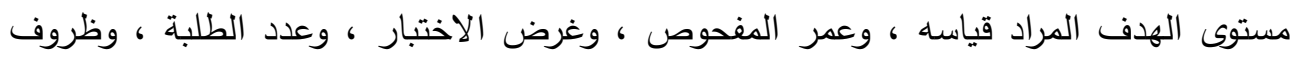

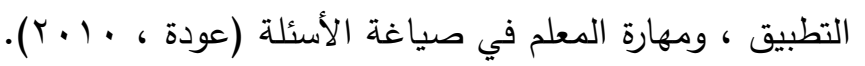

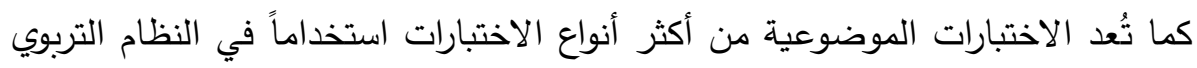

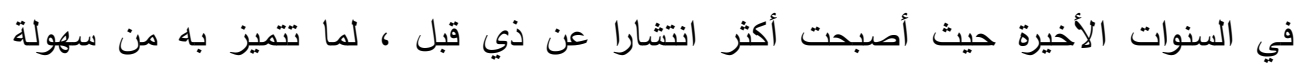
التصحيح ودقته وثباته وموضوعيته ، وإمكانية استخدامها في قياس المستويات المعرفية العليا

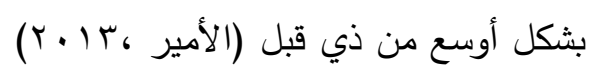
ولعل أهم الاختبارات الموضوعية اختبار الاختيار من متعدد والذي يعتبر من أهم

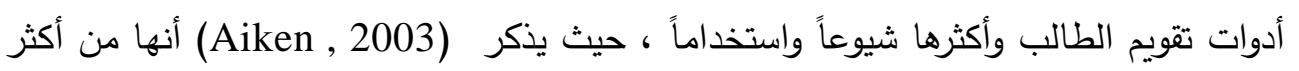

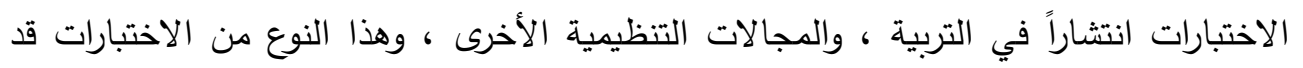

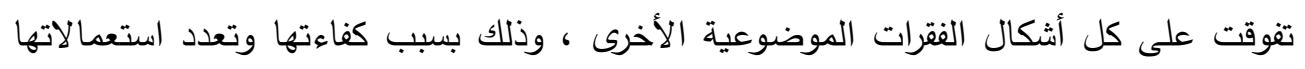
،إذ يمكن بواسطتها قياس أهداف بسيطة وأخرى مركبة في مختلف المواضيع الدراسية.

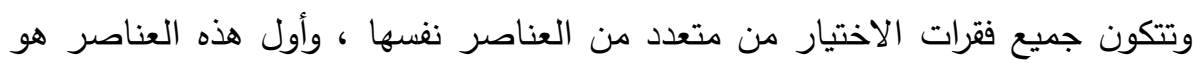

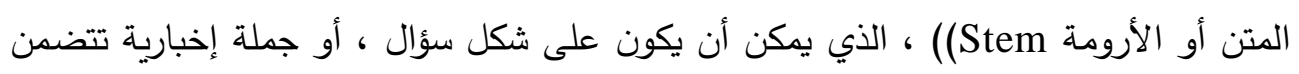

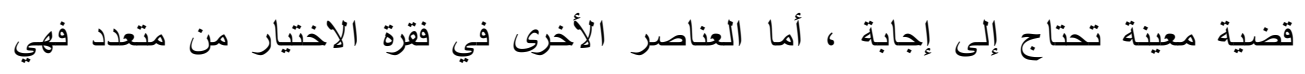

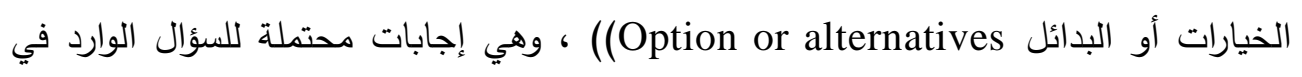

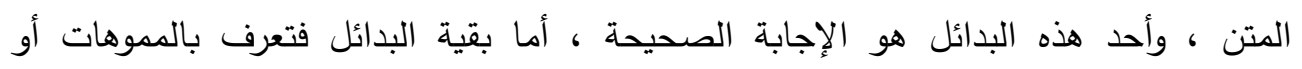
المشتتات (Distracters or Foils) 


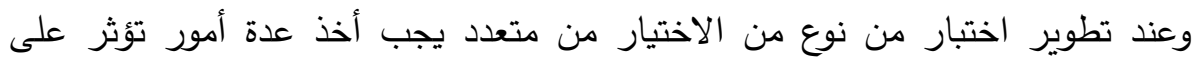

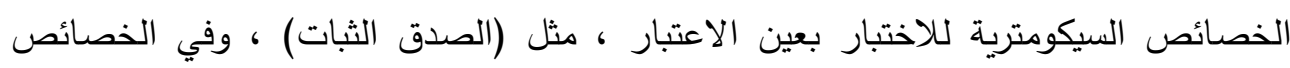

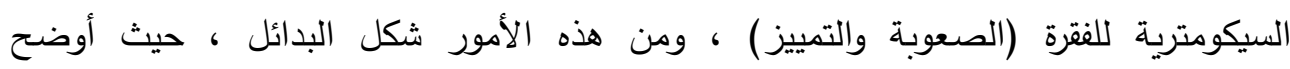
Haladyan \& Crehan)

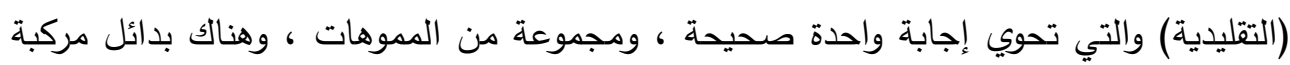

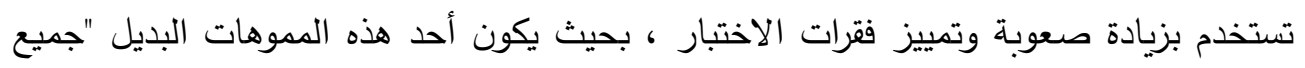

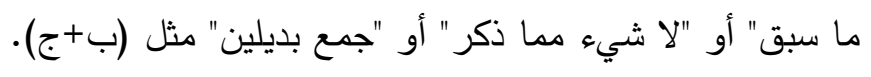

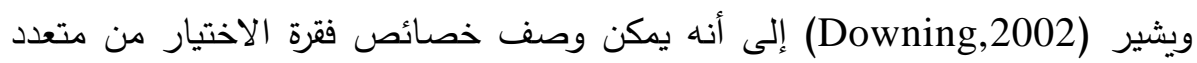

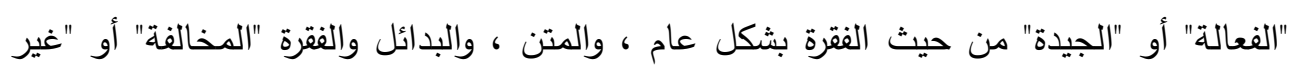

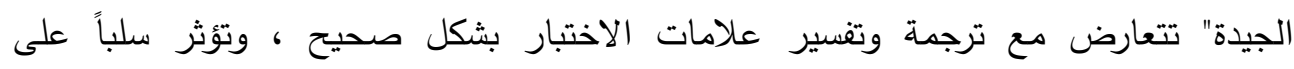
معدلات نجاح الطلاب ، لذلك ومن أجل تطوير اختبارات عالية الصدق والثبات لا بدّ أن يتم

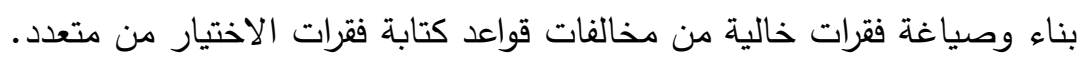

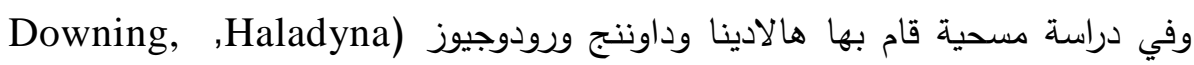

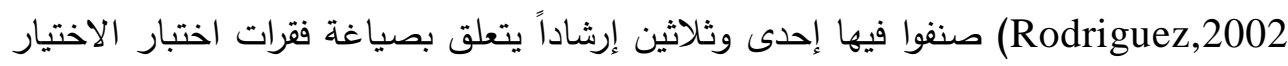

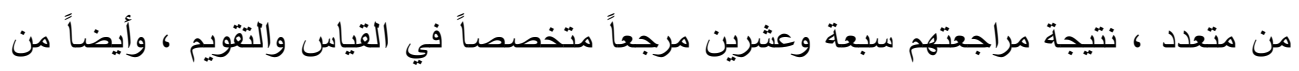

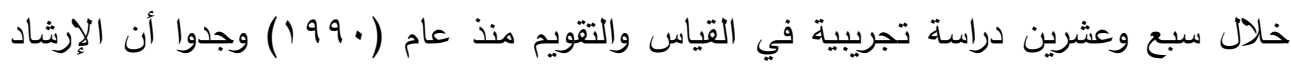
الخامس والعشرين الذي يتعلق بإرشادات كتابة بدائل الفقرة والذي ينص على على أندام أنه (يمكن

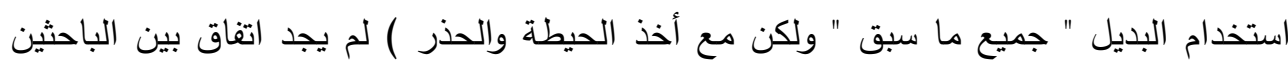

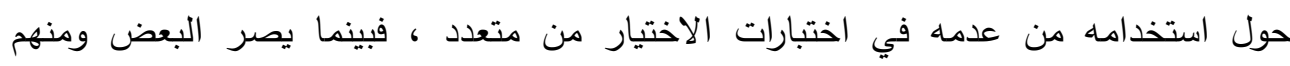

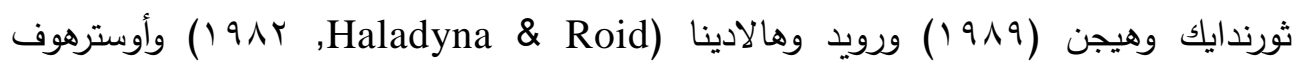

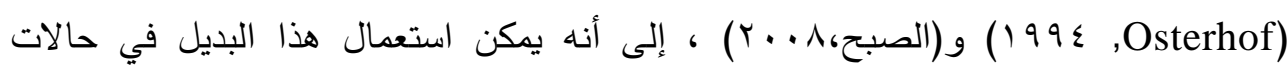

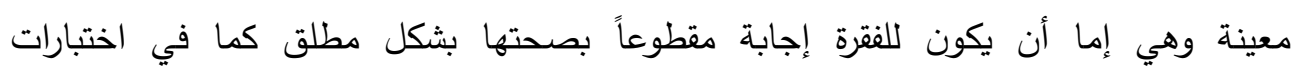

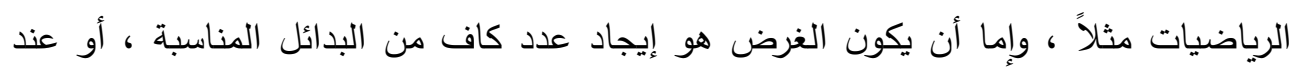

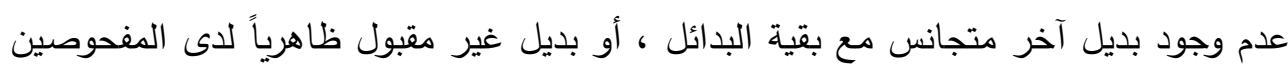

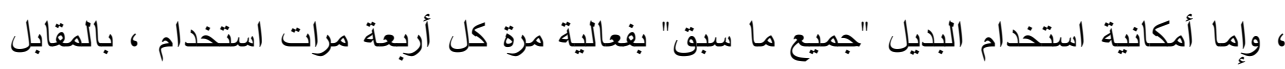

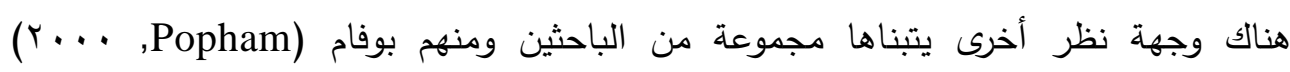
وماكميلان (McMillan, 2004) وهما يؤكدان على ضرورة تجنب هذا البديل ، ويعللون ذلك 
بأنه : يقيس القدرات لدى المفحوص في اختياره أو عدم اختياره ، ولا يقيس معرفة المفدوص

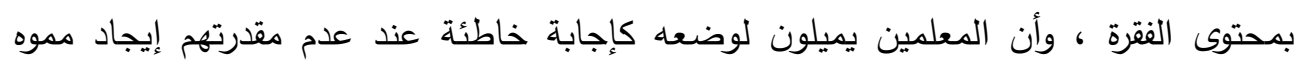

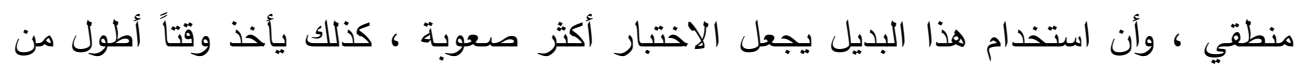

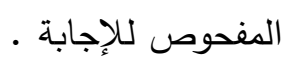

يتضح مما سبق أن استخدام البديل "جميع ما سبق" في فقرات الاختيار من متعدد يدور حوله الكثير من الجدل والخلاف ؛ حيث أن هناك انقسام بين مؤيد ومعارض نتيجة لتأثيره على مدى صعوبة وتمييز وثبات الاختبار ، لذا فإن هذه الدراسة تحاول دراسة أثر استخدام

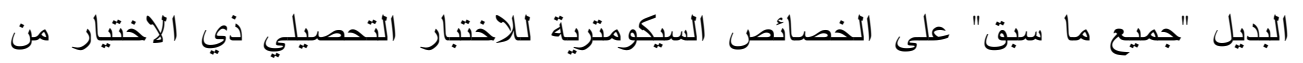
متعدد والذي يعطينا القدرة في الحكم على جودة فقرات الاختبار من متعدد لكي تساعدنا في بناء اختبارات التحصيل بصورة فعالة.

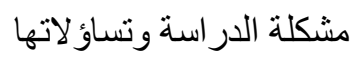

لوحظ من خلال عمل الباحث في الميدان التربوي ، أن بعض المعلمين عند بنائهم لفقرات الاختيار من متعدد في اختبارات التحصيل المدرسية في حيرة من أمرهم حيال الالتزام ببعض قواعد صياغة الفقرات ، ومن بينها قاعدة استخدام البديل "جميع ما سبق" كأحد بدائل فئل

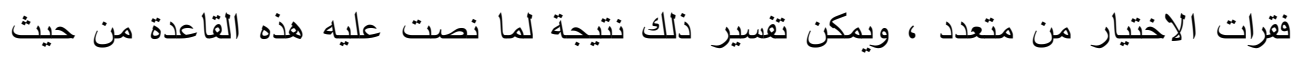
أخذ الحيطة والحذر عند استخدام هذا النوع من البدائل تارة ، والإلزام بعدم استخدامه تارةً

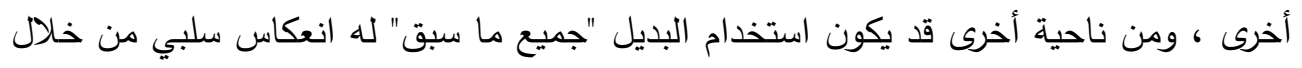
خفض أو زيادة مستوى صعوبة الاختبار • خدانه وهنا تجلت مشكلة الدراسة واقتضت تقصي أثر البديل "جميع ما سبق" على الثى الخصائص

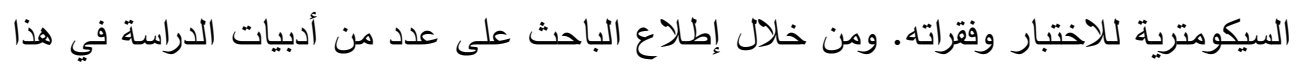

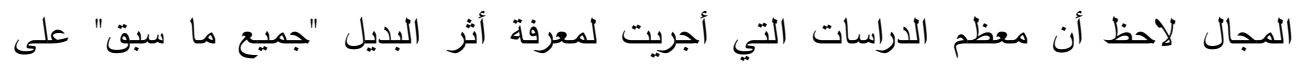

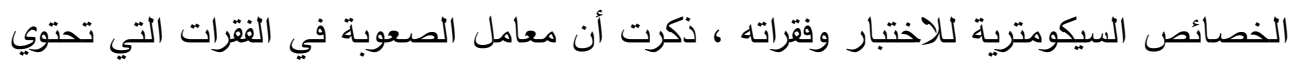

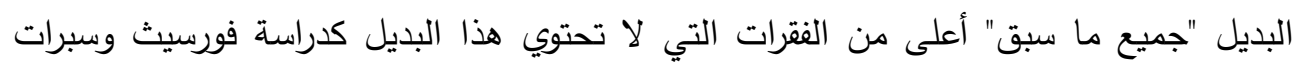
(Fratt,1980 \& Forsyth)

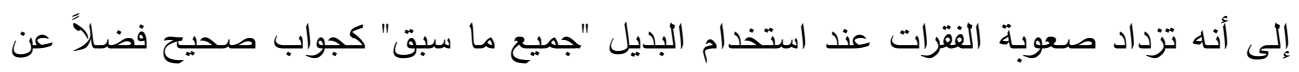

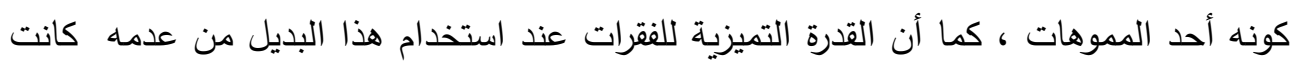
متساويـة. 
ووجد الباحث أيضاً بعض الدراسات التي عارضت الدراسات السابقة ، والتي أثبتت أنه ليس هناك فروق دالة احصائياً في صعوبة الفقرات التي تحتوي البديل "جميع ما سبق" وكان

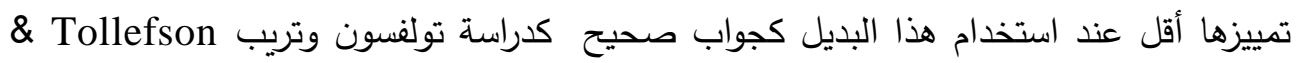

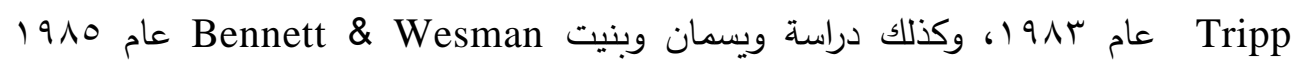
والتي أشارت إليها (Tollefson,1987) والتي أثبتت أن استخدام البديل "جميع ما سبق" ليس له تأثيراً على ثبات الاختبار وصعوبته مقارنة بالبدائل العادية. وبالنظر لما سبق يمكن ملاحظة أن هناك عدم وجود اتساق في نتائج الدراسات التي بالئي

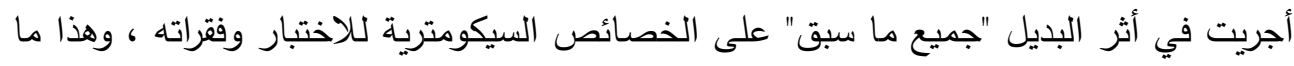

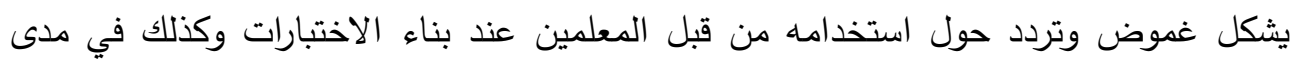

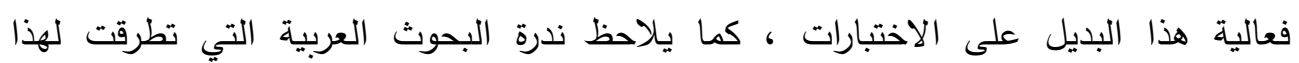

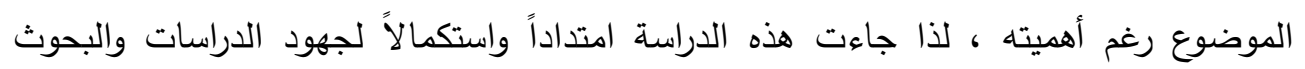

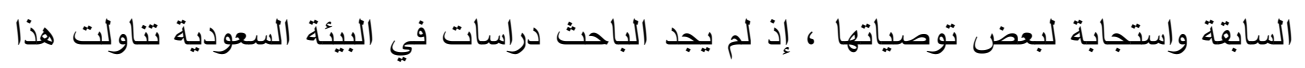
الموضوع ، كما أن هذه الدراسة تحاول معرفة مدى اختلاف الخصائص السيكومترية للاختبار وفقراته إثر وجود البديل "جميع ما سبق" ضمن فقرات الاختيار من متعدد في مادة الرياضيات لدى طلاب الصف الثالث متوسط. ومن ثم تحدد مشكلة الدراسة في محاولة الإجابة على التساؤلات التالية: 1- هل توجد فروق ذات دلالة إحصائية بين متوسطات قيم معاملات الصعوبة في نموذجي الإبه

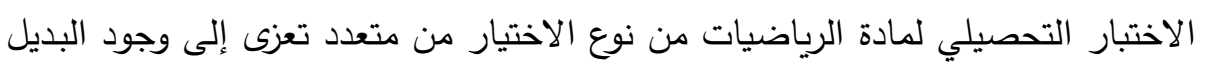

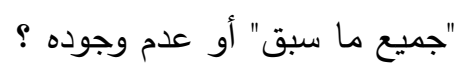

ץ- هل توجد فروق ذات دلالة إحصائية بين متوسطات قيم معاملات التمييز في نموذجي الاختبار التحصيلي لمادة الرياضيات من نوع الاختيار من متعدد تعزى إلى وجود البديل

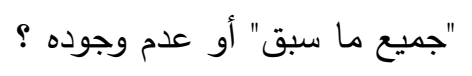

r- هل توجد فروق ذات دلالة إحصائية بين قيم معاملات صدق المدات المحك التلازمي في نتائج

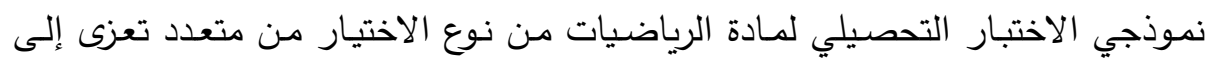

$$
\text { وجود البديل "جميع ما سبق "أو عدم وجوده ؟ }
$$


ع - هل توجد فروق ذات دلالة إحصائية بين قيم معاملات ثبات الاتساق الداخلي في نتائج

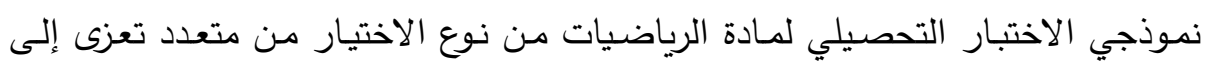

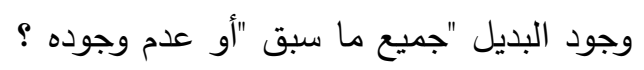

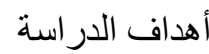

هدفت هذه الدراسة بشكلٍ عام إلى المحاولة لمعرفة أثر البديل "جميع ما سبق" على

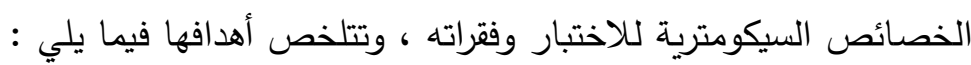

1- التعرف على الفروق بين قيم معاملات الصعوبة في نموذجي الاختبار التحصيلي لمادة

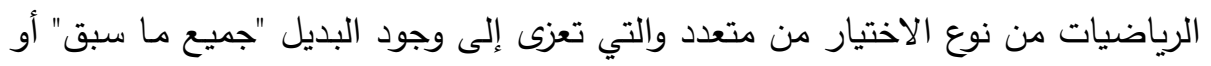

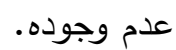

r- التعرف على الفروق بين قيم معاملات التمييز في نموذجي الاختبار التحصيلي لمادة

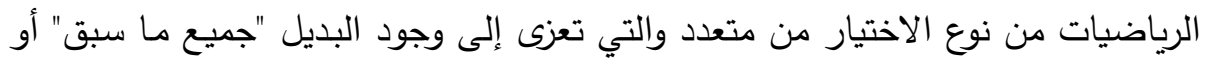

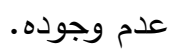

ب- التعرف على الفروق بين قيم معـاملات صـدق المحك التلازمسي في نتائج نمـوذجي الاختبار التحصيلي لمادة الرياضيات من نوع الاختيار من متعدد والتي تعزى إلى وجود

$$
\text { البديل "جميع ما سبق" أو عدم وجوده. }
$$

ع - التعرف على الفروق بـين قيم معـاملات ثبات الاتسـاق الداخلي في نتائج نمـوذجي

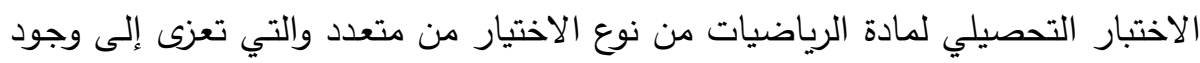

$$
\text { البديل "جميع ما سبق" أو عدم وجوده. }
$$

$$
\text { أهمية الدراسة المايل }
$$

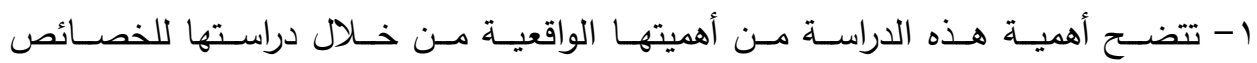

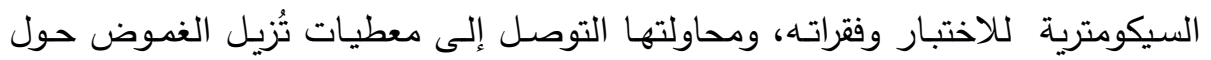
استخدام البديل "جميع مـا سبق"، فهي تضـع لبنـة علميـة تراكمية قد تسـاعد المهتمين بالقياس والتقويم في تجويد بناء اختبارات التحصيل من نوع الاختيار من متعدد بشكل عام ، ومعلمي مادة الرياضيات بشكل خاص. r- تسهم هذه الدراسـة في تقديم أداة قياس جديدة لمعلمي الرياضسيات صـالحة للاستخدام

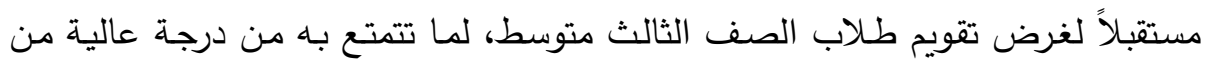
الصدق والثبات والقدرة التميزية. 
r- كونها الدراسـة الأولى - على حد علم الباحث - التي تناولت أثر البديل " جميع مـا سبق " على الخصـائص السيكومترية للاختبار التحصيلي ذي الاختيار من متعدد في لاني

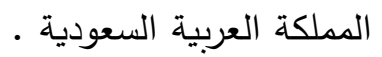

$$
\text { مصطلحات الدر اسة الإجرائية }
$$

: Achievement Test الاختبارات التحصيلية

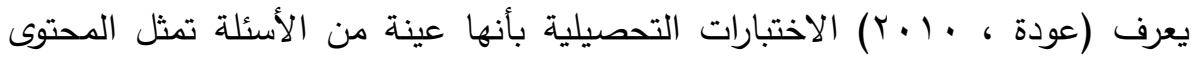
العلمي للمادة الدراسية ، يقوم الطالب بالإجابة عليها لتحديد مستوى تحصيله لمعلومات ومهارات تلك المادة.

ويعرفها الباحث إجرائياً بأنها : الأداة المستخدمة من إعداد الباحث والتي تشتمل على اتى اختبار ذي اختيار من متعدد في الثلاث فصول من مادة الرياضيات للفصل الدراسي الأول

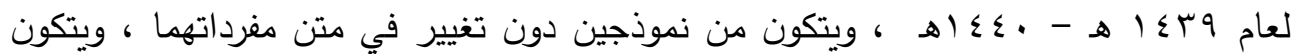

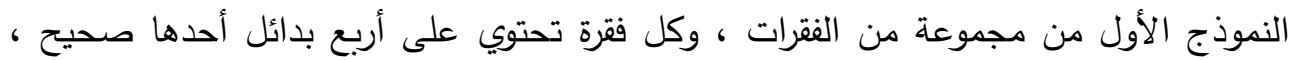

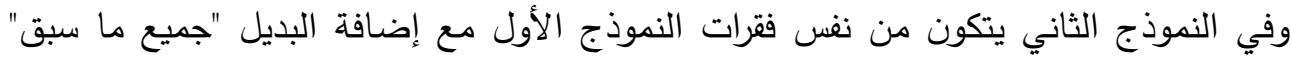

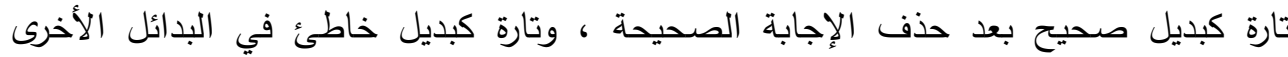

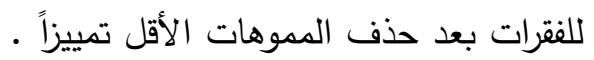

: The Multiple-Choice Tests اختبار الاختيار من متعدد

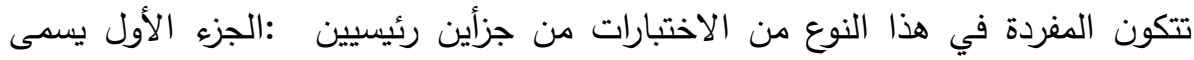

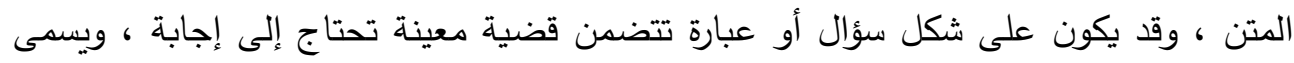

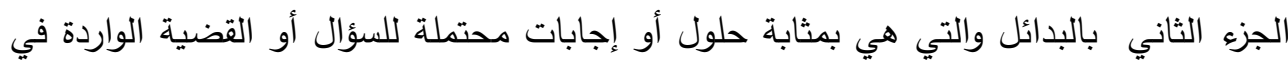

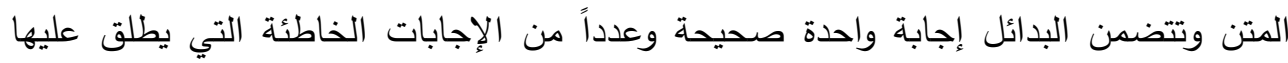

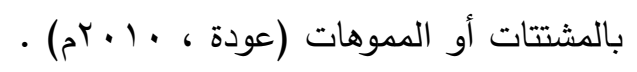

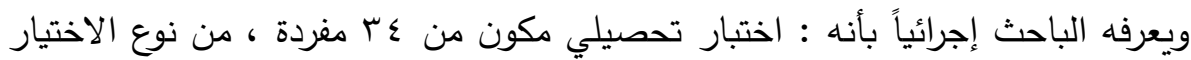

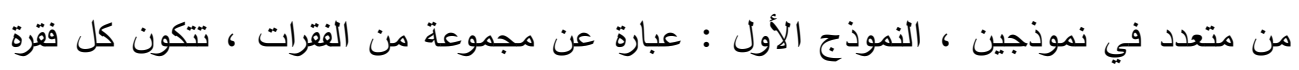

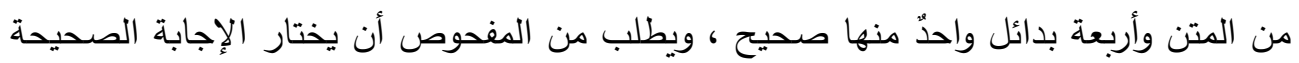

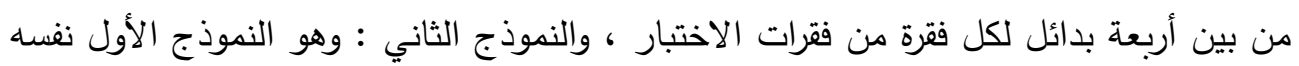
لكن الاختلاف في إضافة البديل "جميع ما سبق" كبديل صحيح بعد حذف الجواب الصحيح من بعض البدائل ، وكبديل خاطئ بعد حذف المموهات الأقل تمييزاً (فاعلية) ، في الثلاث 
فصول (المعادلات الخطية ، العلاقات ،الدوال الخطية) من مادة الرياضيات للفصل الدراسي

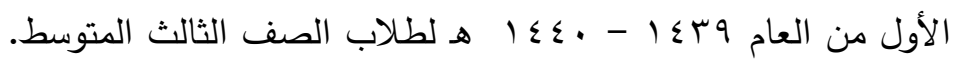

ب المعوبة المفردة Item Difficulty

هي نسبة عدد الأفراد الذين أجابوا إجابة صحيحة على فقرة ما بالنسبة للعدد الكلي

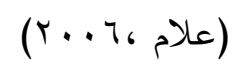

التعريف الإجرائي: يقصد بصعوبة الفقرة وفق النظرية الكلاسيكية هي نسبة الطلاب الذين أجابوا إجابة صحيحة عن كل فقرة من فقرات الاختبار من بين الطلاب الذين حاولوا

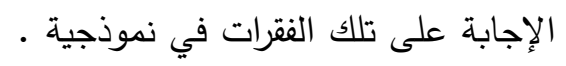

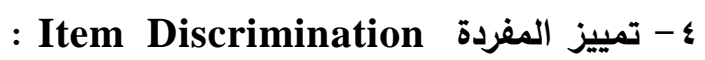

يشير معامل التمييز إلى قدرة الفقرة على التمييز بين من يمتلكون المعرفة ومن لا

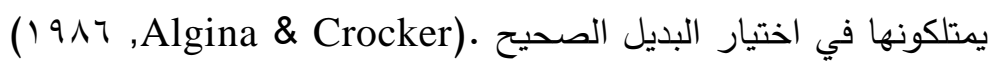

التعريف الإجرائي : يقصد بتمييز الفقرة وفق النظرية الكلاسيكية هو قيمة معامل

الارتباط بين درجة الفرد على الفقرة مع درجته الكلية على الاختبار مقاساً بمعامل الارتباط

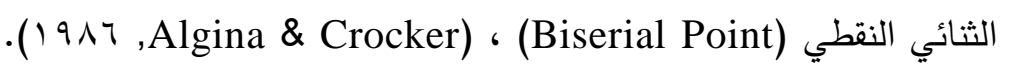

ه : Reliability الثبات

هو حصول الفرد على نفس الدرجات إذا طبق عليه نفس الأداة وتحت نفس الظروف.

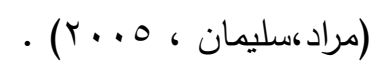

التعريف الإجرائي للثبات : يقصد به في هذه الدراسة معامل ثبات الاتساق الداخلي

$$
\text { للاختبار محسوب باستخدام طريقة كودر - ريتثاردسون (· (Y) (KR-20). }
$$

: Validity الصدق

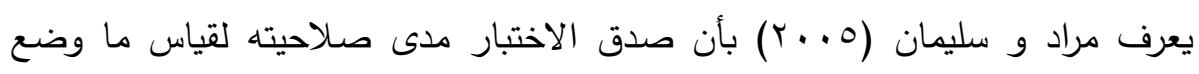

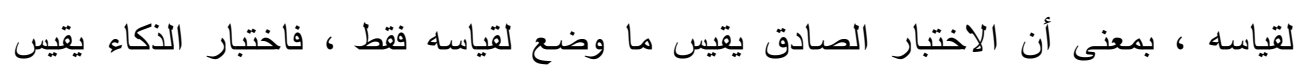

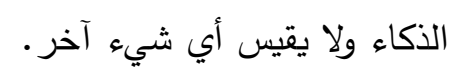

التعريف الإجرائي للصدق : يقصد به في هذه الدراسة صدق المحك التلازمي ، وهو

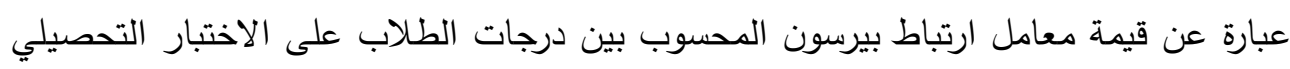

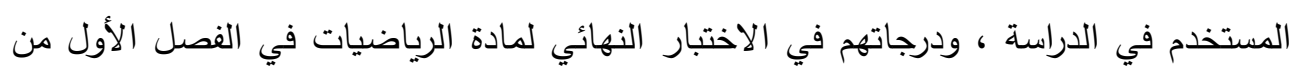

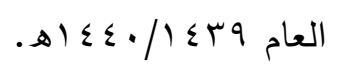


حدود موضوعية : اقتصار الدراسة على أثر البديل "جميع ما سبق" على الخصائص

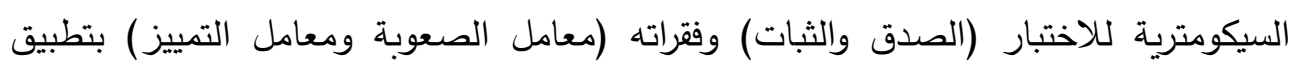

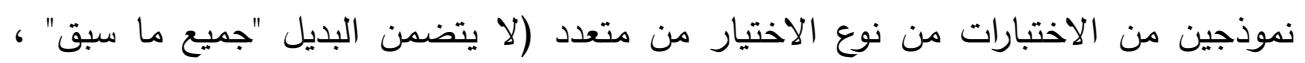

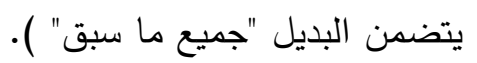
حدود مكانية : الإدارة العامة للتعليم بمدينة مكة المكرمة.

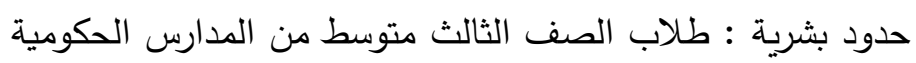

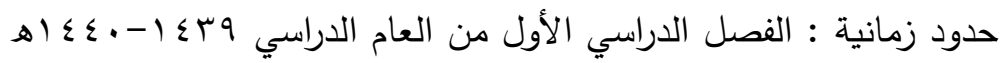
منهج الدراسة :

لتحقيق أهداف هذه الدراسة اعتمدت هذا الدراسة على المنهج الوصفي المقارن الذي

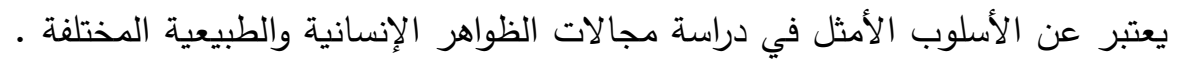
مجتمع الدر اسة : من الاسلئ

يتكون مجتمع الدراسة من جميع طلاب الصف الثالث متوسط بالمدارس الحكومية

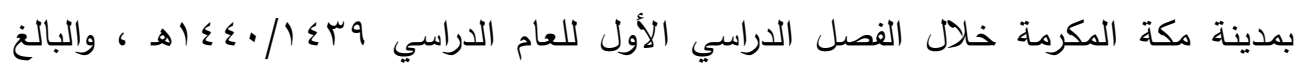
عددهم بحسب الرجوع إلى التقرير الإحصائي التربوي السنوي من إدارة تقنية المعلومات

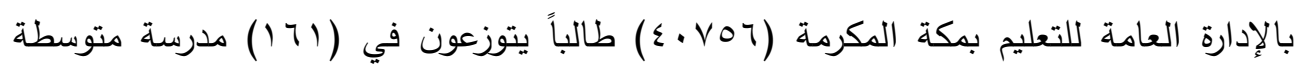
أمينة الدراسة. أ- عينة الاراسة الاستطلاعية: تكونت من ( · . (1) طالب من طلاب الصف الثالث متوسط بمدينة مكة المكرمة ، وذلك

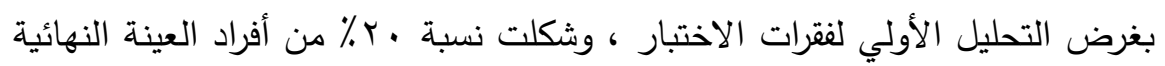

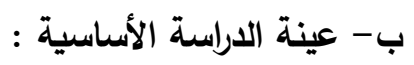
تم اختيار عينة الدراسة بطريقة العينة الطبقية العشوائية حتى تكون العينة ممثلة

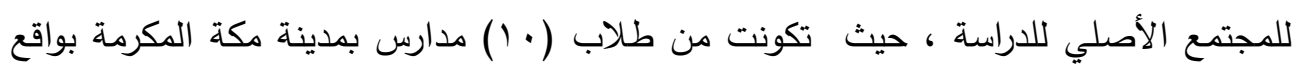

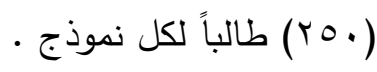
أداة الدر اسة : ولتحقيق أهداف الدراسة وهي اختبار أثر البديل "جميع ما سبق" على صدق وثبات اختبار تحصيلي ذي اختيار من متعدد في مادة الرياضيات وعلى معاملي الصعوبة والتمييز 
لكفرداته،قام الباحث ببناء اختبارتحصيلي في مادة الرياضيات للصف الثالث متوسط الفصل

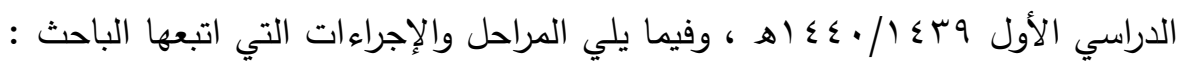
أولاً : تحديد الموضوعات المراد قياسها : الاول

اختار الباحث ثلاث فصول دراسية من مادة الرياضيات لطلاب الصف الثالث متوسط

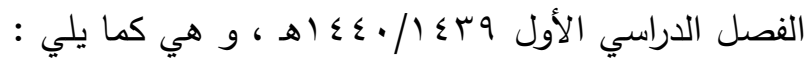

$$
\begin{aligned}
& \text { الفصل الأول : المعادلات الخطية. }
\end{aligned}
$$

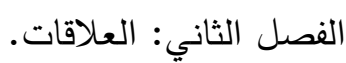

$$
\begin{aligned}
& \text { الفصل الثالث: الدوال الخطية . الثعل }
\end{aligned}
$$

ويرجع السبب في اختيار الباحث لهذا المنهج الدراسي ؛ لأنه تخصص الباحث في

$$
\text { المجال التدريسي. }
$$

ثانياً : تحديد الأهداف السلوكية :

قام الباحث بتحديد الأهداف السلوكية التي تقيس محتوى الفصل الأول والثاني والثالث من مادة الرياضيات لطلاب الصف الثالث متوسط بالفصل الدراسي الاول ، وقد استفاد

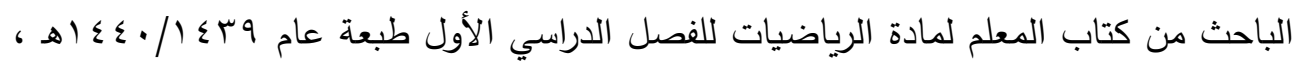

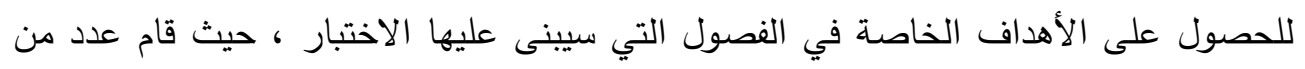

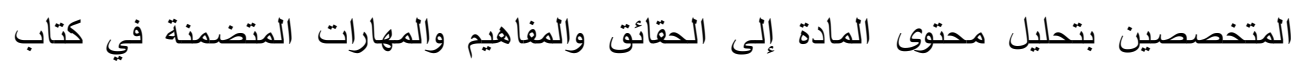

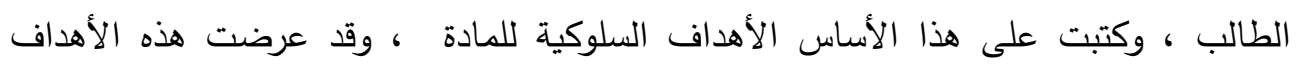

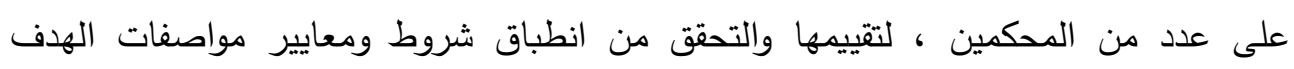

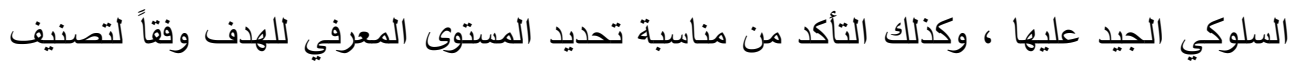

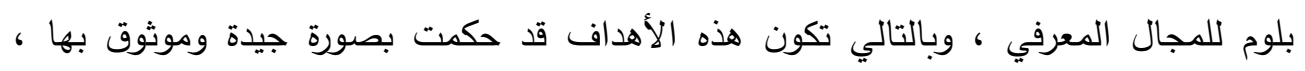
ويمكن للباحث الاعتماد عليها في بناء دراسته. ثالثاً : إعداد جدول المواصفات : لإحات لإعداد جدول الموصفات قام الباحث بالخطوات التالية : أ- تحديد الوزن النسبي للأهداف السلوكية بمستوياتها المختلفة:

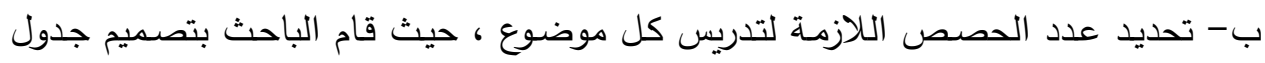

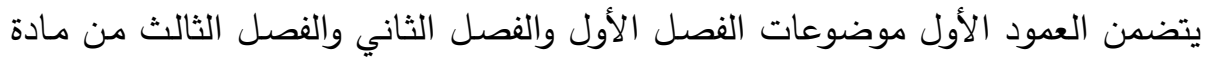

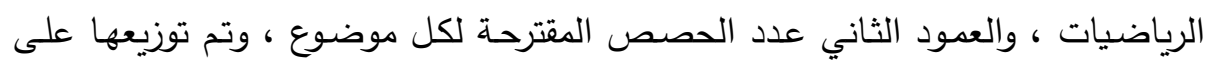


عدد من المشرفين التربويين وعدد من معلمي الرياضيات للصف الثالث متوسط، ومن

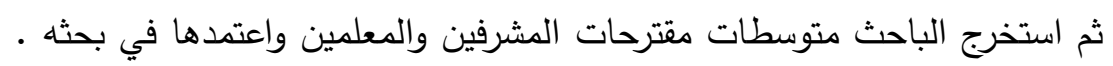
ج- تحديد الوزن النسبي لموضوعات المادة الدراسية.

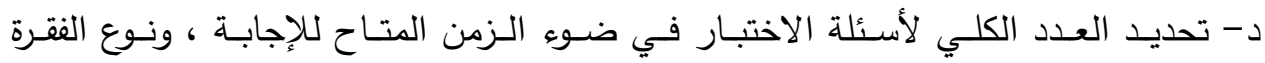

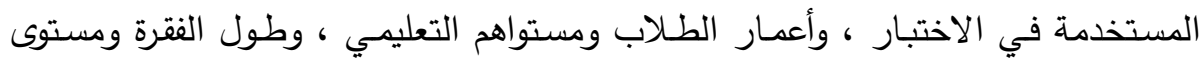

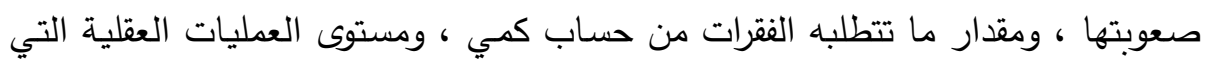
تقيسها الفترة. هـ - حساب عدد الأسئلة في كل موضوع لكل مستوى من مستويات الاهداف . و - تحديد درجة أسئلة كل موضوع في كل مستوى من مستويات الأهداف . . وتوصل الباحث إلى جدول المواصفات التالي جدول (1) : جدول (1):

مواصفات الاختبار التحصيلي للوحدة الأولى والثانية والثالثة للفصل الاراسي الأول من مادة الرياضيات لطلاب الصف الثالث المتوسط للعام 9 سـ اهـ - . ـ ؛ أهـ

\begin{tabular}{|c|c|c|c|c|c|c|c|c|c|c|c|}
\hline \multirow{2}{*}{ لاللموضوان النسبية } & \multirow{2}{*}{ اللارجات } & \multirow{2}{*}{ مجموع } & \multicolumn{6}{|c|}{ الأهداف } & \multirow{2}{*}{ والألسئلة } & \multirow{2}{*}{ الوحدات } & \multirow[t]{2}{*}{ م } \\
\hline & & & تقويم & تركيب & تحليل & تطبيق & فهم | مهم & تذكر & & & \\
\hline \multirow[t]{2}{*}{$\%$ r. } & \multirow[t]{2}{*}{$\wedge$} & \multirow[t]{2}{*}{$\wedge$} & . & . & 1 & . & $r$ & $\varepsilon$ & الأسئلة & \multirow{2}{*}{ المعادلات الخطية الأول } & \multirow[t]{2}{*}{1} \\
\hline & & & . & . & 1 & . & $r$ & $\varepsilon$ & الدرجة & & \\
\hline \multirow[t]{2}{*}{$\%$. } & \multirow[t]{2}{*}{$\varepsilon$} & \multirow[t]{2}{*}{$\varepsilon$} & . & . & . & . & r & r & الأسئلة & \multirow{2}{*}{ الفعلاقات الثاني } & \multirow[t]{2}{*}{ r } \\
\hline & & & . & . & . & . & r & r & الارجة & & \\
\hline \multirow[t]{6}{*}{$\% 1$. } & \multirow[t]{4}{*}{$\varepsilon$} & \multirow[t]{4}{*}{$\varepsilon$} & . & . & . & . & $r$ & $r$ & الأسئلة & \multirow{4}{*}{ الدوال الخطية الثالث } & $r$ \\
\hline & & & . & . & . & . & $r$ & r & الارجة & & \\
\hline & & & . & $\cdot$ & . & . & $r$ & $r$ & الدرجة & & \\
\hline & & & - & . & . & - & . & . & الارجة & & \\
\hline & & $\varepsilon$. & . & $\cdot$ & $r$ & . & iv & $r$. & \multicolumn{2}{|c|}{ مجموع الأسئلة } & \\
\hline & $\Leftrightarrow$ & & · & . & $r$ & . & iv & r. & \multicolumn{2}{|c|}{ مجموع اللارجات } & \\
\hline$\% 1 \ldots$ & & & $\%$ & $\%$ & $\% 9$ & $\%$ & $\%$ « । & $\%$. & \multicolumn{2}{|c|}{ الأوزان النسبية للأهداف } & \\
\hline
\end{tabular}
رابعاً : كتابة وصياغة الأسئلة :

قام الباحث بكتابة وصياغة اختباراً تحصيلياً مكون من (0ء ) فقرة من نوع الاختيار من متعدد بأربعة بدائل ، واحد منها فقط صحيح ، أي أن الإجابة تأخذ إحدى القيميتين (•، أ) وذلك في مادة الرياضيات لطلاب الصف الثالث متوسط، في الفصل الأول (المعادلات

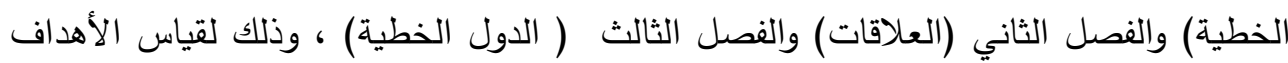
الواردة في جدول المواصفات ، مرتبة وفقاً لتسلسل عرض المحتوى . 
خامساً : تحكيم أداة الدراسة :

للتأكد من صدق محتوى فقرات الاختبار قام الباحث بتحليل فقرات الاختبار بغرض التاه

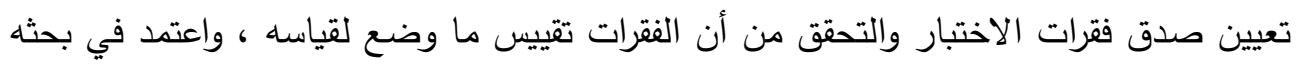

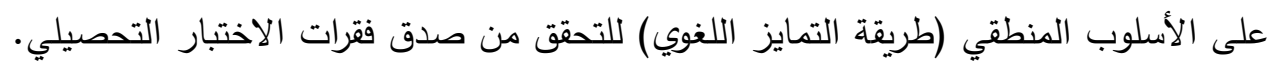
ويرجع اختيار الباحث لهذه الطريقة لعدة اعتبارات منها :

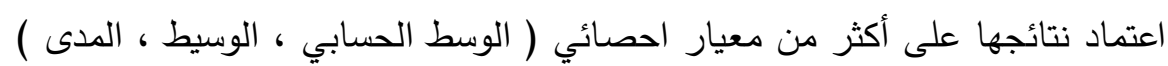
سهولة الحصول على استجابات المحكمين عدم احتياجها إلى عمليات إحصائية معقدة لتحليل نتائجها. وفيما يلي بيان تفصيلي بالخطوات التي اتبعها الباحث في تنفيذ اجراءات الطريقة : 1- قام الباحث ببناء استبيان يشتمل على ثلاثة أقسام : (القسم الاول : يضم أربع فقرات

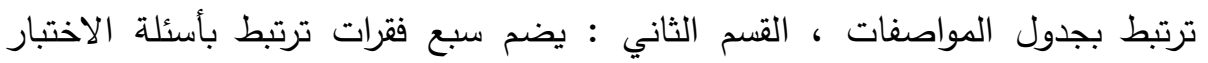

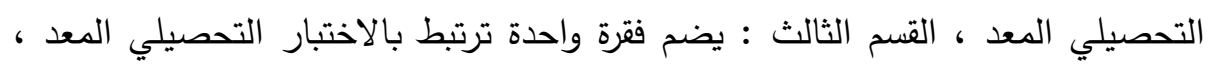
ومقياس تدريجي لكل قسم يمتد من (1) إلى (0) حيث يشير العدد (1) إلى أدنى ارتباط

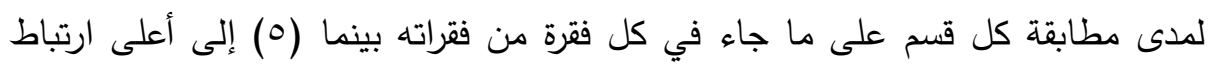
في كل قسم على ما جاء في كل فقرة من فقراته.

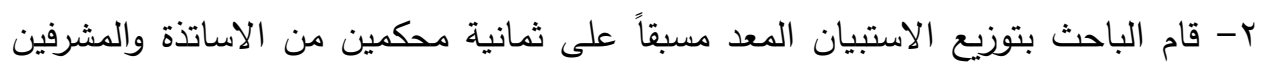

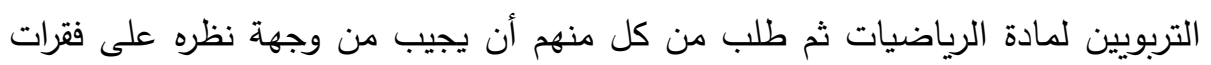
الاستبيان بأقسامه الثلاث. r- قام الباحث بعد الحصول على استجابات المحكمين بتفريغها في جدول خاص ، لحساب المتوسطات الحسابية لكل فقرة يشتمل عليها كل قسم من أقسام الاستبيان.

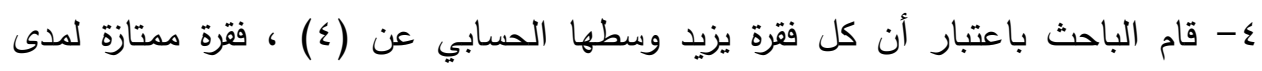

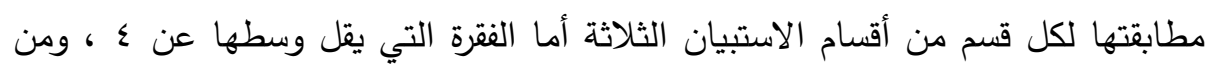

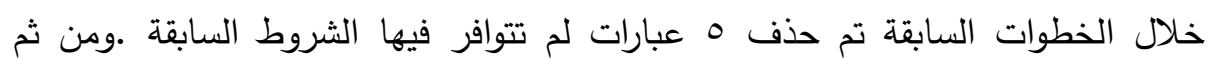

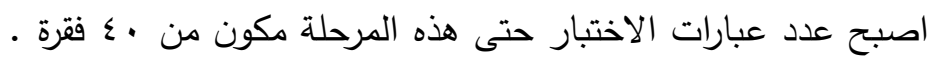
سادساً : التجربة الاستطلاعية : قام الباحث بتطبيق الاختبار المكون من ·ـ •ـ فقرة على عينة استطلاعية تكونت من

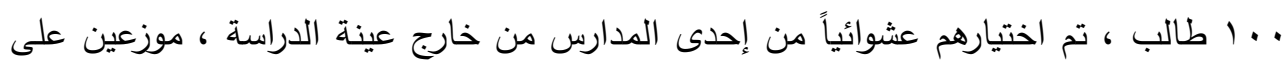




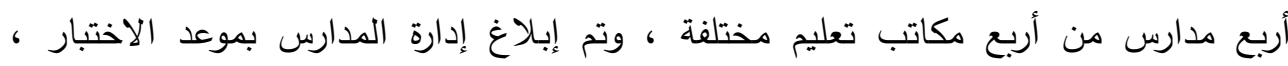

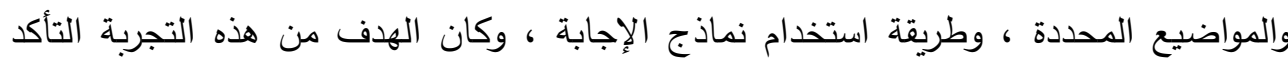

من وضوح تعليمات الاختبار ، وتحديد الزمن المناسب ، والتحليل الأولي لفقرات الاختبار .

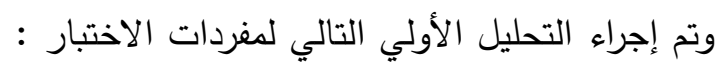

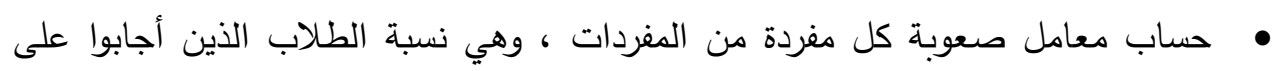

$$
\text { المفردة إجابة صحيحة }
$$

• حساب معامل تمييز كل مفردة من المفردات وهو معامل الارتباط بين نتائج المفحوصين

$$
\begin{aligned}
& \text { على كل فقرة ونتائجهم على الاختبار الكلي } \\
& \text { • حساب فعالية المموهات ( المشتتات) }
\end{aligned}
$$

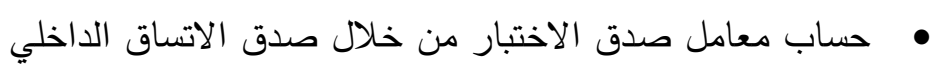

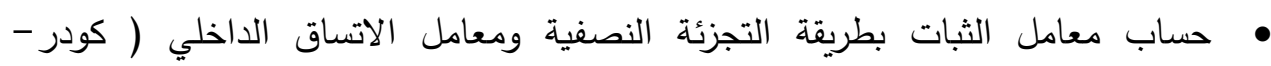

ريتشاردسون) وذلك لمناسبته للفقرات التي إجابتها ( ، 1 ( ) )

يتضح من الخطوات السابقة أن معاملات الصعوبة في نموذج الصورة الأولية للاختبار

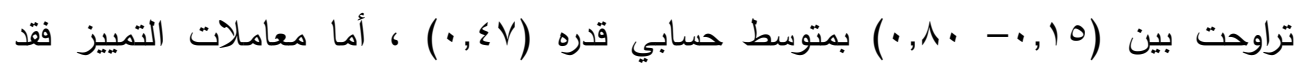

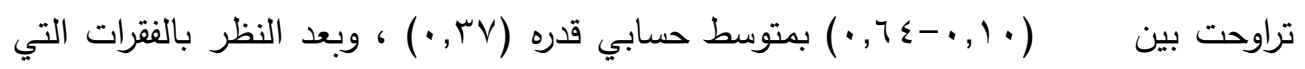

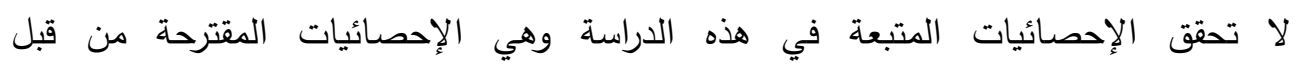

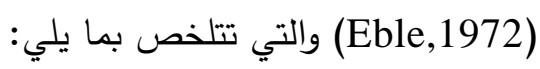

• الفقرات التي معامل تمييزها (سالب) تحذف ولات داعي للاحتفاظ بها.

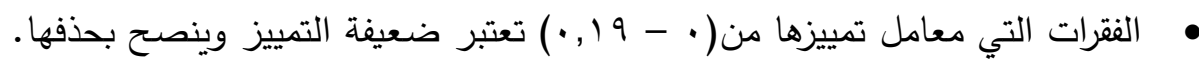

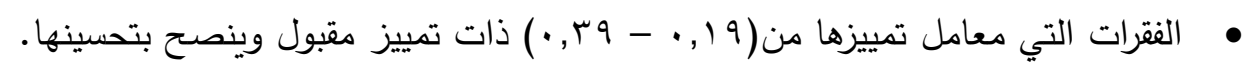

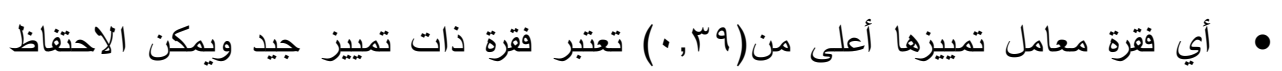

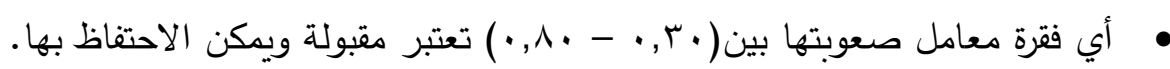

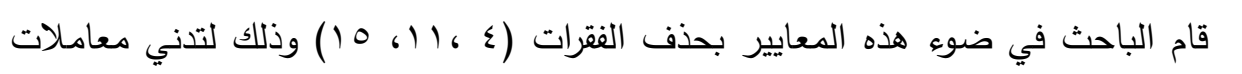

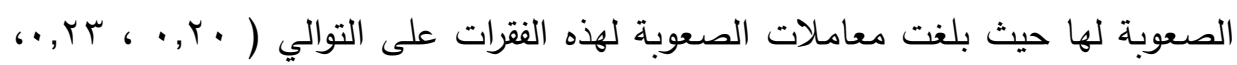

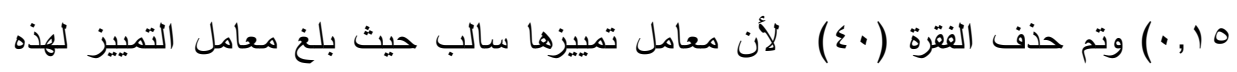

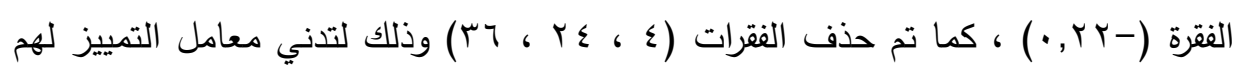




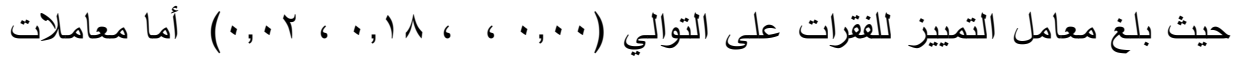

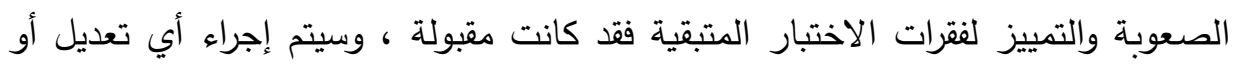
تحسين على هذه الفقرات في نموذج الصورة الأولية للاختبار .

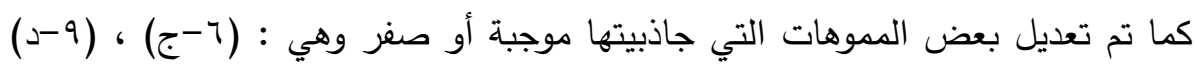

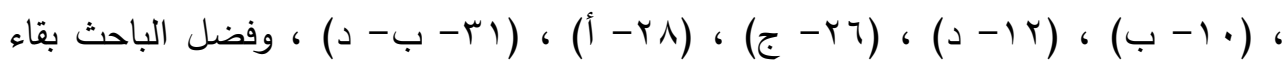
المموه (1/ إ- ب) كما هو وذلك لتتاسقه مع بقي المموهات في الفقرة نفسها. كما اعتمد الباحث في تحديد صدق الاختبار على صدق الاتساق الداخلي حيث تم

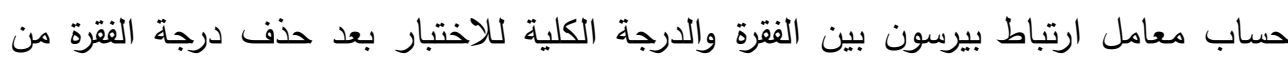

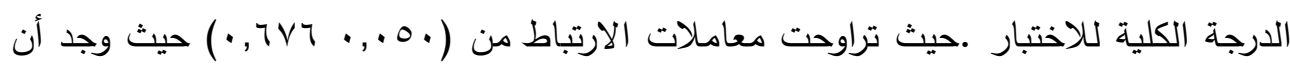

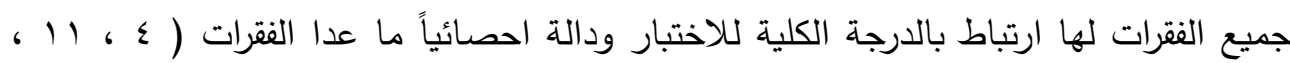

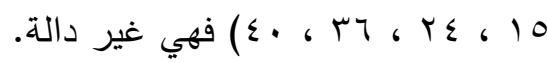
كما تم حساب ثبات الاختبار باستخدام معادلة كودر - ريتشاردسون (KR-20) وطريقة

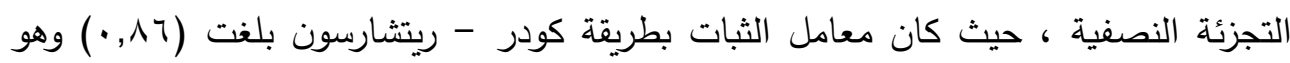

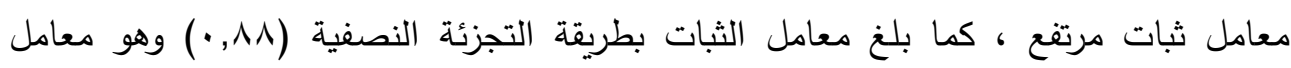

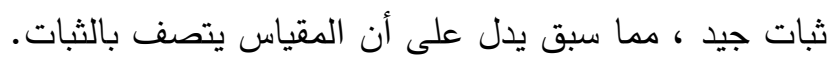

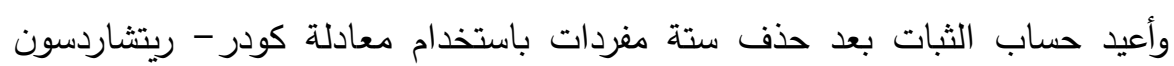

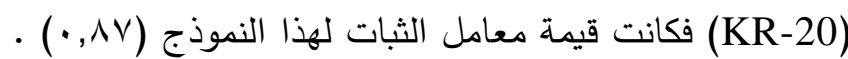
وفي ضوء التجربة الاستطلاعية تم تكوين نموذجين للاختبار نفسه ، يتكون كل منها

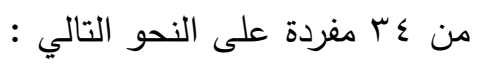
النموذج الأول : احتوت كل مفردة من مفرداته على أربعة بدائل عادية.

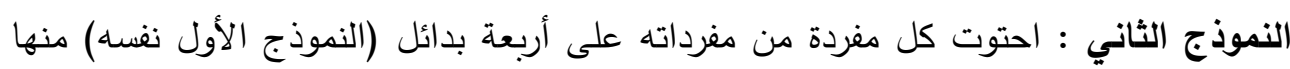

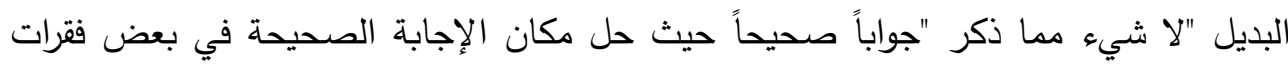

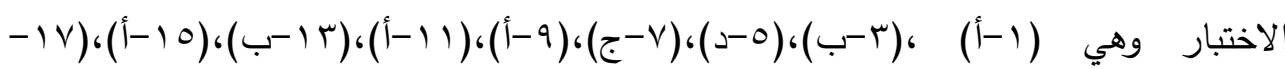

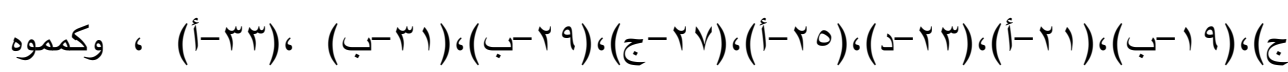

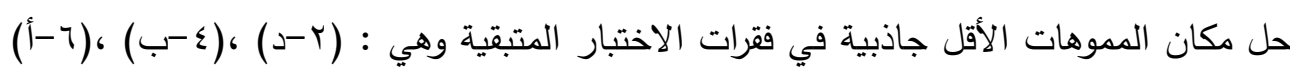

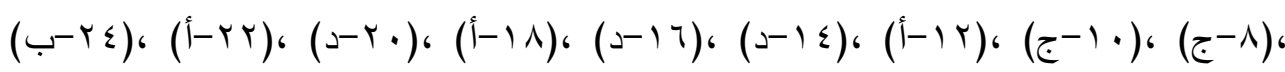




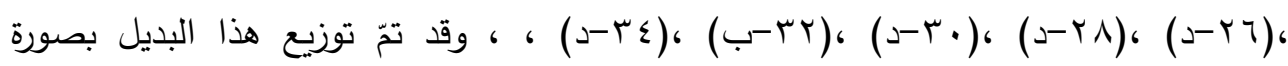

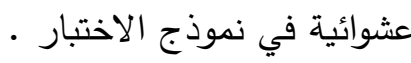

المعالجة الإحصائية:

على ضوء تساؤلات الدراسة استخدم الباحث في الدراسة الحالية مجموعة من الأساليب

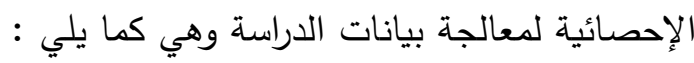

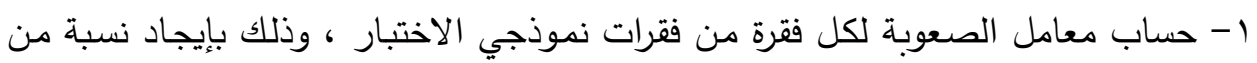

أجاب عن الفقرة إجابة صحيحة ممن حاولوا الإجابة عليها.

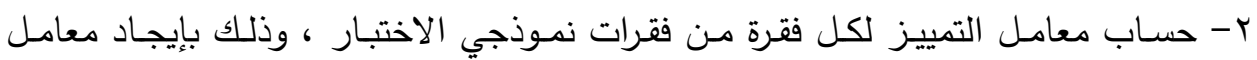

الارتباط بين نتائج المفحوصين على هذه الفقرة ونتائجهم على الاختبار الكلي.

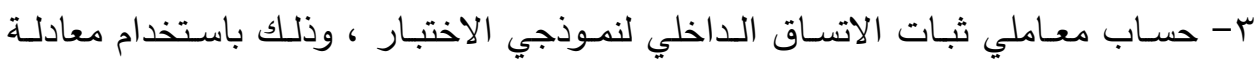

$$
\text { كودر - ريتشاردسون (r-KR) (r-KR). }
$$

ـ - حسـاب معـاملي صـدق المحك التلازمسي ، وذلك بحســاب معامـل ارتبـاط بيرسـون بين

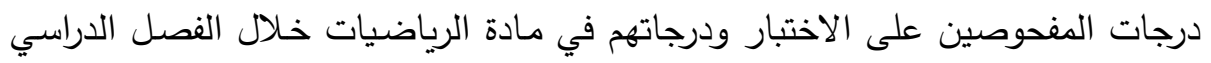

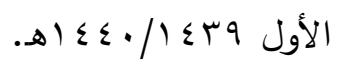

ه- استخدام اختبار t لفحص الفروق بين قيم متوسطات معاملات الصعوبة وقيم متوسطات

$$
\text { معاملات التمييز لفقرات نموذجي الاختبار . }
$$

צ- استخدام الإحصائي (FeldtF,1969) لفحص مدى الاختلاف في معاملي ثبات الاتساق

$$
\text { الداخلي لعينتين مستقلتين لنموذجي الاختبار . الإحساتي }
$$

V- اسـتخدام الإحصــئي (Z-Fisher) للكثـف عـن الفـروق الثنائيـة بـين معـاملي صـدق

$$
\text { المحك التلازمي لنموذجي الاختبار • الإسماتس }
$$

نتائج الدر اسة وتفسير ها

في هذا الفصل يتناول الباحث عرض نتائج التحليلات الإحصائية التي توصل إليها.

وتفسير هذه النتائج من خلال التحقق من صحة تساؤلات الدراسة وذلك على النحو التالي :

$$
\text { التساؤل الأول : التعير هده }
$$

هل توجد فروق ذات دلالة إحصائية بين متوسطات قيم معاملات الصعوبة في نموذجي

الاختبار التحصيلي لمادة الرياضيات من نوع الاختيار من متعدد تعزى إلى وجود البديل

$$
\text { "جميع ما سبق" أو عدم وجوده ؟ الاخئ }
$$


للتحقق من التساؤل الأول تمّ حساب معاملات الصعوبة للفقرات في نموذجي الاختبار وذلك بإيجاد نسبة الطلبة الذين أجابوا عن الفقرة إجابة صحيحة من بين المفحوصين الذين

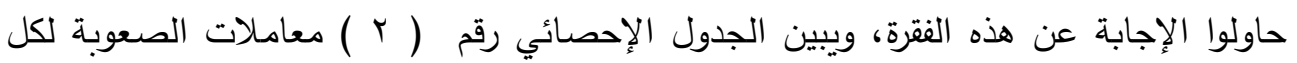

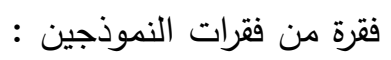

جدول (Y) : معاملات صعوبة الفقرات في نموذجي الاختبار

\begin{tabular}{|c|c|c|c|c|c|c|c|}
\hline \multicolumn{4}{|c|}{ نموذج تتضمن بدائل فقراته البديل } & \multicolumn{3}{|c|}{ نموذج لا تتضمن بدائل فقراته البديل } & \multirow{2}{*}{ رقلم الاختبار } \\
\hline الصعوبة & رقم الفقرة & الصعوبة & رقم النقرة & الصعوبة & رقم الفقرة & معامل الصعوبة & \\
\hline ., $₫ 9$ & 11 &.,$r \varepsilon$ & 1 &., 0. & 11 &., 77 & 1 \\
\hline., 17 & 19 & $\cdot, \leqslant 9$ & r &., 0 & 19 & r, $\leqslant r$ & $r$ \\
\hline$\cdot, Y \wedge$ & $r$. &., 09 & $r$ & .,$\varepsilon \wedge$ & $r$. & r & $r$ \\
\hline., 17 & r) & . & $\varepsilon$ &.,$r \lambda$ & rI & $\cdot, v$. & $\varepsilon$ \\
\hline., 0. & Kr & $\cdot, 01$ & 。 & ., & $r r$ & .,$\leqslant V$ & 。 \\
\hline$\cdot, 1 \wedge$ & $r r$ & , r & 7 &.,$r_{0}$ & $r r$ &., 01 & 7 \\
\hline., 0 & $r \varepsilon$ & ., $\varepsilon_{0}$ & v &., 0 & $r \varepsilon$ & $\cdot, r \wedge$ & v \\
\hline., 07 & ro & , ro & $\wedge$ &., $0 \wedge$ & ro & . & $\Lambda$ \\
\hline$\cdot, Y V$ & ry & ז'ו, & 9 & ., «^ & T &., 09 & 9 \\
\hline ז זו, & TV & ., & 1. & . r r & TV & . & 1. \\
\hline$\cdot, r$. & $r \wedge$ &., 00 & 11 & $\cdot, \varepsilon 1$ & ru &., 01 & 11 \\
\hline ת & rq & •,r. & Ir &., 0 & rq & ., & Ir \\
\hline$\cdot, \leqslant 7$ & $r$. & , & 14 & . & $r$. &., $0 \mathrm{~V}$ & 15 \\
\hline., $1 r$ & $r$ & $\cdot, r)$ & $1 \leqslant$ &.,$r 4$ & $r$ & $\cdot, \varepsilon$ & $1 \varepsilon$ \\
\hline . & rt & ., $\leqslant 0$ & 10 & . & rt & .,$\varepsilon r$ & 10 \\
\hline זו, & rr &., 19 & 17 & $\cdot, 7)$ & rr & Tr, & 17 \\
\hline
\end{tabular}

يتضح من الجدول السابق أن قيم معاملات الصعوبة لفقرات النموذج الذي لا تتضمن

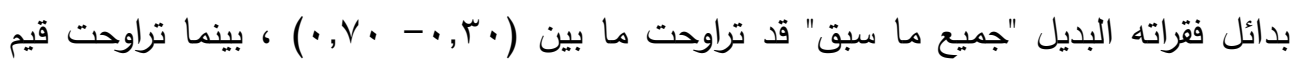

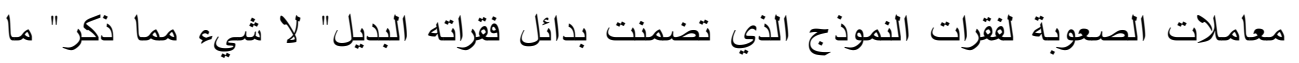

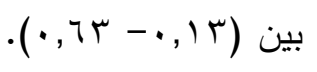

وللكثف عن الفروق في معامل صعوبة الفقرات تبعاً لنموذجي الاختبار ، تم إجراء

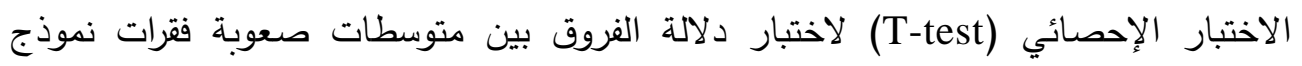

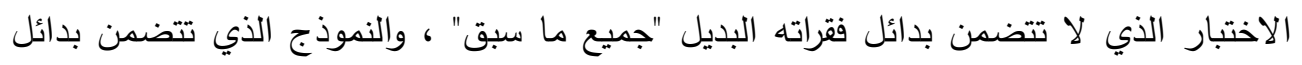

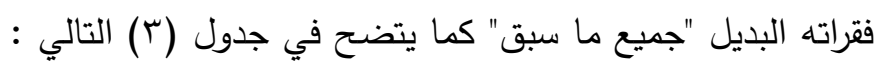


جلول (r) : نتائج اختبار (ت) لفحص الفروق بين متوسطي معاملات صعوبة فقرات نموذجي الاختبار

\begin{tabular}{|c|c|c|c|c|c|c|c|}
\hline الدلالة & قيمة اختبار ت & درجة الحرية & الانحراف المعياري & الكتوسط الحسابي & العدد & 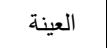 & \\
\hline \multirow{2}{*}{$\cdot, \cdot r$} & \multirow{2}{*}{$r, r v$} & \multirow{2}{*}{74} & $\cdot, 1$. & $\cdot, \varepsilon \vee$ & $r \varepsilon$ & | نموذج 1 & 1 \\
\hline & & &., 10 & $\cdot, r q$ & $r \varepsilon$ & نموذج r & $r$ \\
\hline
\end{tabular}

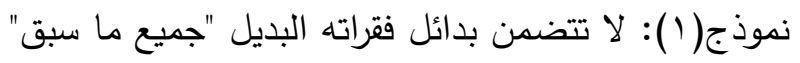

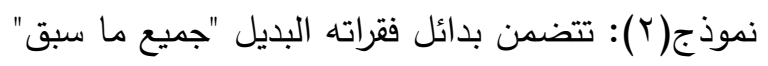
من جدول (r) السابق يتضح وجود فروق دالة إحصائياً بين قيم معاملات صعوبية

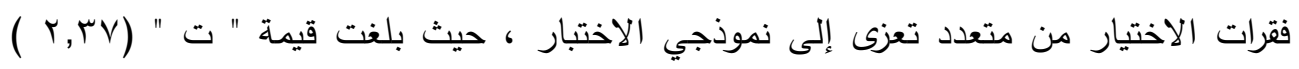

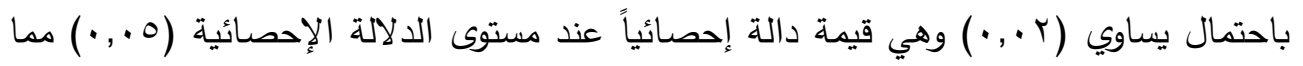

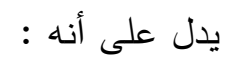

توجد فروق ذات دلالة إحصائية بين متوسطات قيم معاملات الصعوبة في نماذج

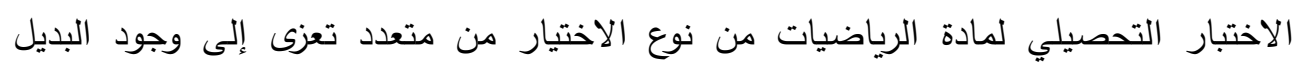

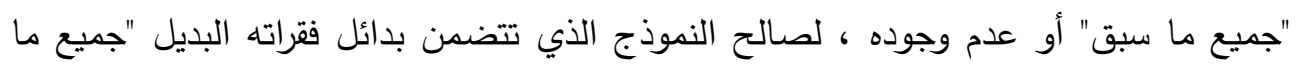
سبق".

كما يتضح من قيم متوسطات معاملات صعوبة الفقرات أن متوسط معامل صعوبة

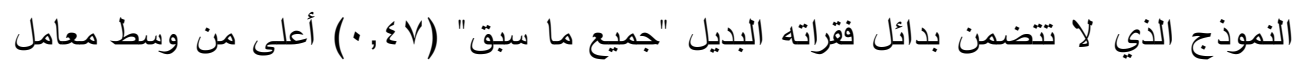

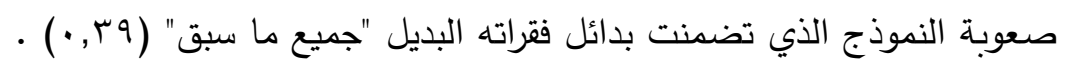
ويمكن تفسير نتيجة التساؤل الأول على النحو التالي : أظهرت نتائج اختبار (ت) لفحص الفروق بين متوسطي صعوبة فقرات نموذجي

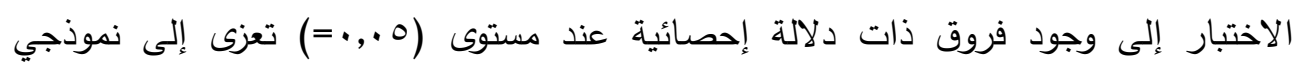

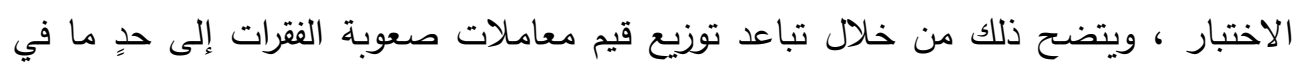
هذين النموذجين. كما لاحظ الباحث أنّ عدد الفقرات التي تقل عن معامل الصعوبة (0, •) في النموذج

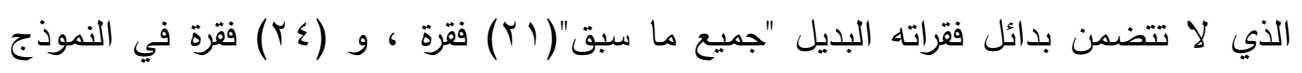

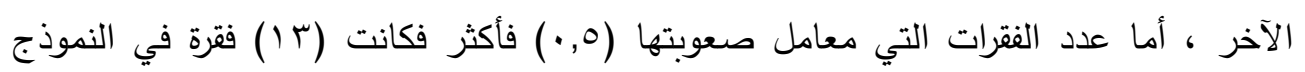


الذي لا تتضمن بدائل فقراته البديل "جميع ما سبق"، و ( • () فقرة في النموذج الآخر ، وهذا

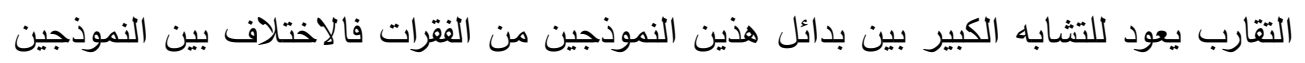
فقط في تضمين البديل "جميع ما سبق" من بين بدائل الفقرة ، فالجواب الصحيح موجود تارةً لئل

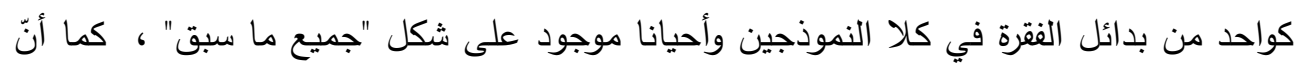

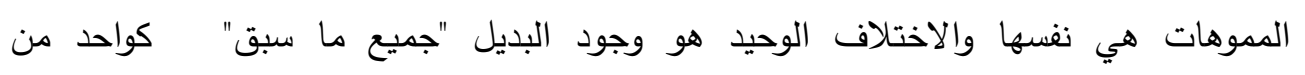

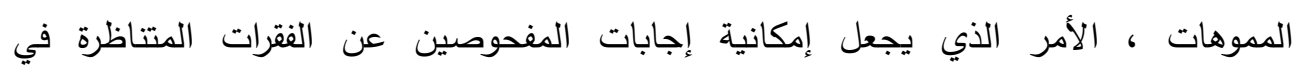

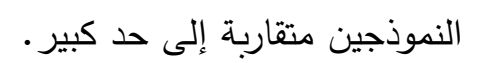

واتفقت هذه النتيجة مع نتائج عدد من الدراسات السابقة كدراسة كل من أوسترهوف وكوتس (Coats,1984 \& Oosterhof) ، توليفسون (Tollefson,1987) ، كرهان وآخرون \& Haladyna , Crehan) كريهان وهالادينا وبريور ، (et al.,1989 Crehan)

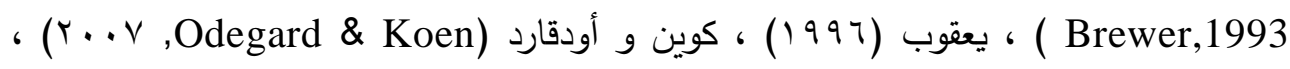

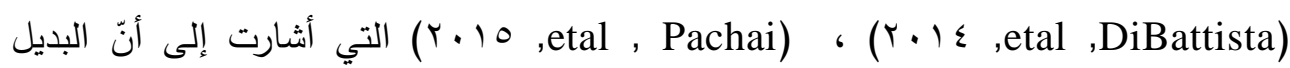

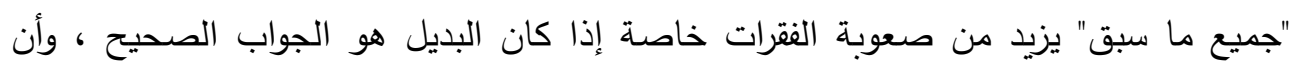

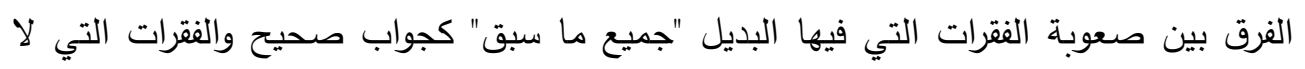

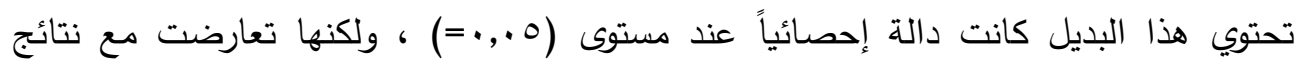

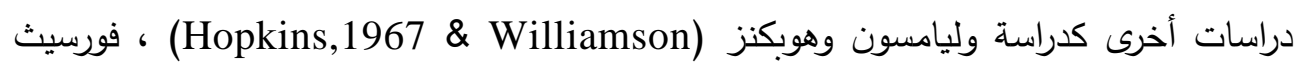

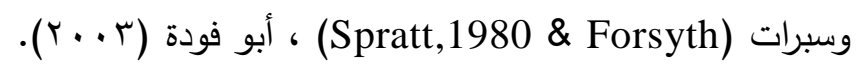

التساؤل الثاني : هل توجد فروق ذات دلالة إحصائية بين متوسطات قيم معاملات التمييز في نموذجي

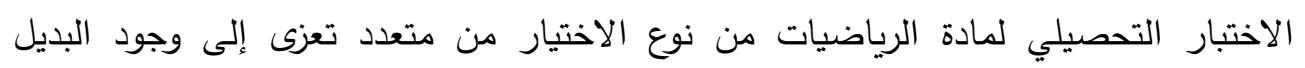
"جميع ما سبق" أو عدم وجوده ؟ للتحقق من التساؤل الثاني تم حساب معاملات التمييز لكل فقرة في نموذجي الاختبار وذلك بإيجاد معامل الارتباط بين نتائج المفحوصين على كل فقرة من فقرات الاختبار ونتائجهم

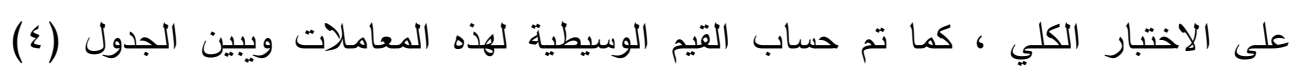
معامل التمييز لكل فقرة من فقرات نموذجي الاختبار . 


\begin{tabular}{|c|c|c|c|c|c|c|c|}
\hline \multicolumn{8}{|c|}{ جدول (ع ) :معاملات تمييز الفقرات في نموذجي الاختبار } \\
\hline \multicolumn{4}{|c|}{ نموذج تتضمن بدائل فقراته البديل } & \multicolumn{3}{|c|}{ نموذج لا تتضمن بدائل فقراته البديل } & \multirow{2}{*}{ رقاختبار } \\
\hline معامل التمييز & رقم الفقرة & معامل التمييز & رقم الفقرة & معامل التمييز & رقم الفقرة & معامل التمييز & \\
\hline$\cdot, \varepsilon r$ & 11 & 0.32 & 1 & 0.50 & 11 & 0.45 & 1 \\
\hline$\cdot, r 9$ & 19 & 0.40 & $r$ & 0.55 & 19 & 0.41 & $r$ \\
\hline$\cdot, \leqslant 9$ & $r$. & 0.24 & $r$ & 0.27 & r. & 0.32 & $r$ \\
\hline$\cdot, r \varepsilon$ & rI & 0.59 & $\varepsilon$ & 0.44 & rI & 0.47 & $\varepsilon$ \\
\hline$\cdot, \varepsilon V$ & rr & 0.54 & 。 & 0.40 & rY & 0.45 & 0 \\
\hline$\cdot, r$. & r & 0.56 & 1 & 0.38 & r & 0.39 & 7 \\
\hline$\cdot, \leqslant 9$ & $r \varepsilon$ & 0.31 & v & 0.52 & $r \varepsilon$ & 0.40 & v \\
\hline$\cdot, \varepsilon$ & ro & 0.49 & $\wedge$ & 0.40 & ro & 0.53 & $\wedge$ \\
\hline$\cdot, \Sigma V$ & ry & 0.51 & 9 & 0.44 & r & 0.60 & 9 \\
\hline$\cdot, \varepsilon r$ & rV & 0.19 & 1. & 0.19 & rV & 0.34 & 1. \\
\hline$\cdot$, rV & rA & 0.39 & 11 & 0.47 & r^ & 0.47 & 11 \\
\hline ., OV & rq & 0.43 & ir & 0.49 & rq & 0.33 & ir \\
\hline$\cdot$, ҮA & $r$. & 0.47 & 14 & 0.30 & $r$. & 0.49 & ir \\
\hline$\cdot, 19$ & r & 0.42 & $1 \leqslant$ & 0.29 & r & 0.42 & $1 \varepsilon$ \\
\hline$\cdot, r)$ & rr & 0.19 & 10 & 0.30 & rr & 0.45 & 10 \\
\hline$\cdot, \varepsilon$. & r & 0.33 & 17 & 0.54 & זr & 0.27 & 17 \\
\hline., 0 . & $r \varepsilon$ & 0.47 & IV & 0.49 & $r \varepsilon$ & 0.19 & iv \\
\hline
\end{tabular}

يتضح من خلال الجدول السابق أنّ قيم معاملات التمييز لفقرات النموذج الذي لا تتضمن بدائل فقراته البديل "جميع ما سبق" قد تراوحت ما بين (9 (1, • - . ج, • ) ، بينما تراوحت

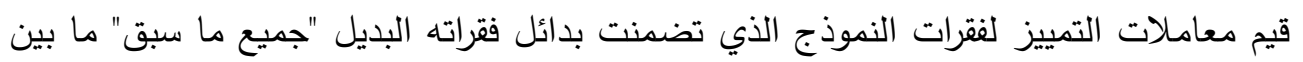
$\cdot(\cdot, 09-\cdot, 19)$

وللكثف عن الفروق في معامل تمييز الفقرات تبعاً لنموذجي الاختبار ، تم إجراء الاختبار الإحصائي (T-test) لاختبار دلالة الفروق بين متوسطات تمييز فقرات نموذج

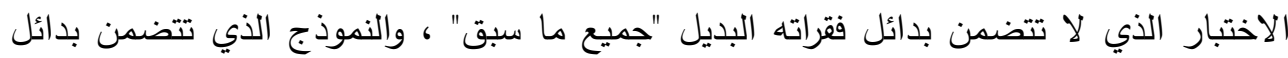

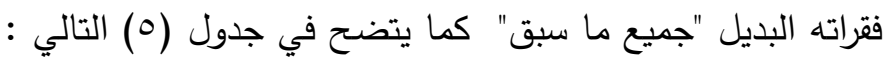




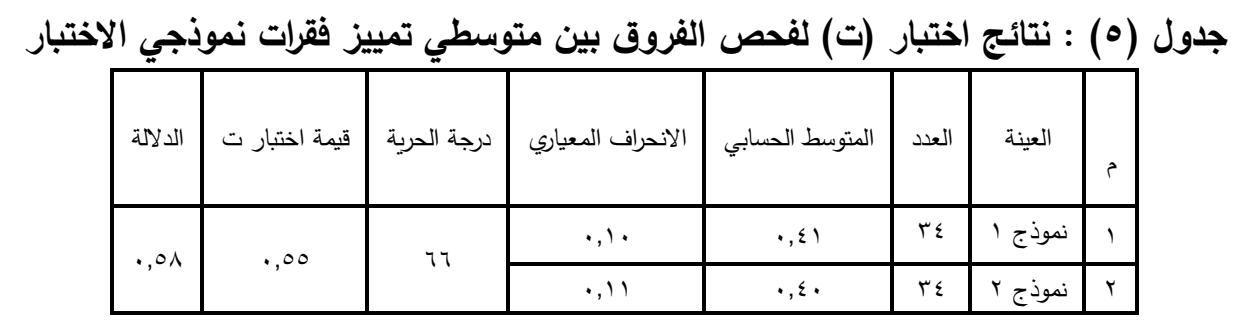

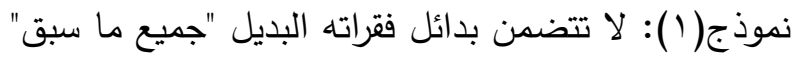

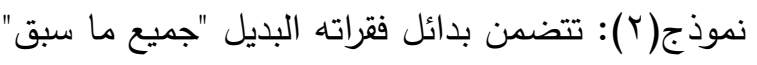
من جدول (0) السابق يتضح عدم وجود فروق دالة إحصائياً بين قيم معاملات تمييز فقرات الاختيار من متعدد تعزى إلى نموذجي الاختبار ، حيث بلغت قيمة " ت " (00, • )

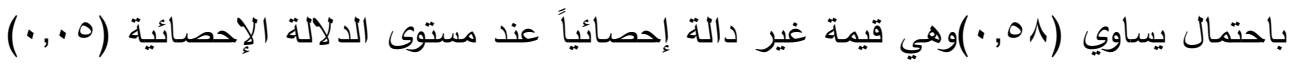

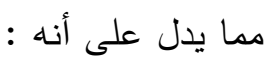
لا توجد فروق ذات دلالة إحصائية بين متوسطات قيم معاملات التمييز في نموذجي

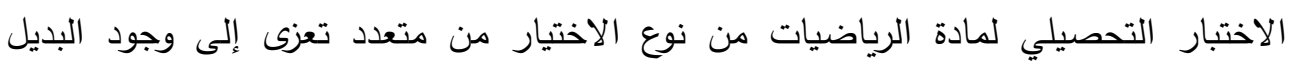

$$
\text { "جميع ما سبق" أو عدم وجوده ؟ }
$$

كما يتضح من قيم متوسطات معاملات تمييز الفقرات أنها تساوت في فقرات النموذج

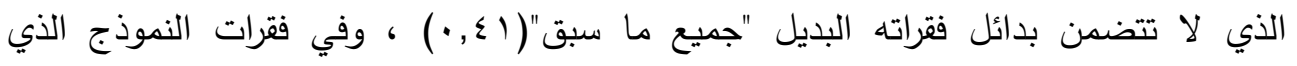

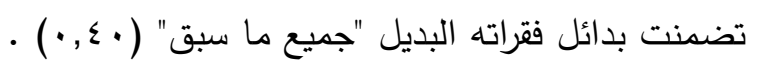

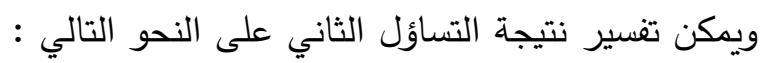
أظهرت نتائج اختبار (ت) لفحص الفروق بين متوسطي تمييز فقرات نموذجي الاختبار إلى عدم وجود فروق ذات دلالة إحصائية عند مستوى (0.,.=) تعزى إلى نموذجي الاختبار ، ويتضح ذلك من تقارب توزيع قيم معاملات تمييز الفقرات في هذين النموذجين.

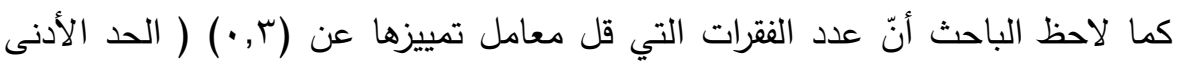
المفضل في قيم تمييز الفقرات) كان (0) فقرات في النموذج الذي لا تتضمن بدائل فقراته

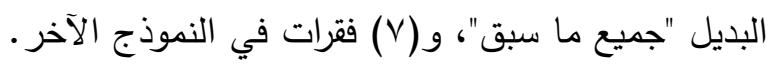

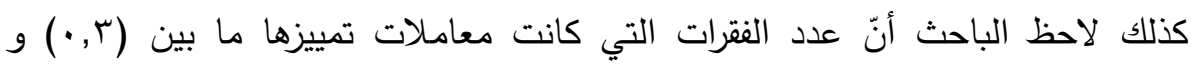
(9 §, •) كان متقارباً في النموذجي ، أما عدد الفقرات التي كانت معاملات تمييزها (0, •)

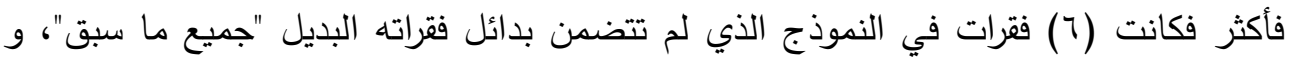


(7) فقرات في النموذج الآخر ، وتتفق هذه النتيجة مع دراسة كل توليفسون (Tollefson,1987) \& Crehan,Haladyna) ودراسة كريهان وهان وادينا وبريور (Frary,1991) .(Brewer, 1993 التساؤل الثالث : هل توجد فروق ذات دلالة إحصائية بين قيم معاملات صدق المحك التلازمي في نتائج

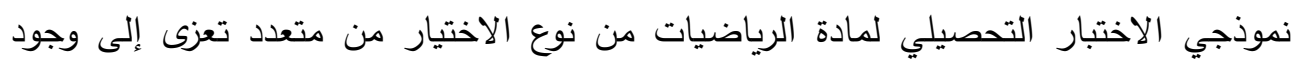

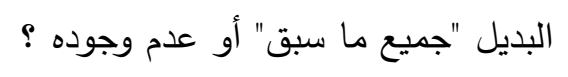
للتحقق من التساؤل الثالث تمّ حساب معامل صدق مدود المحك التلازمي لنموذجي اختبار الاختيار من متعدد وذلك بحساب معامل ارتباط بيرسون بين درجات الطلاب على النموذجين

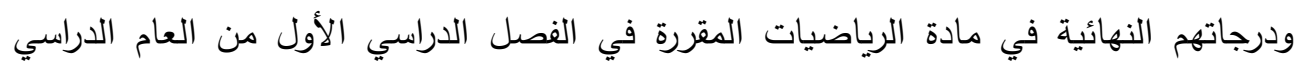

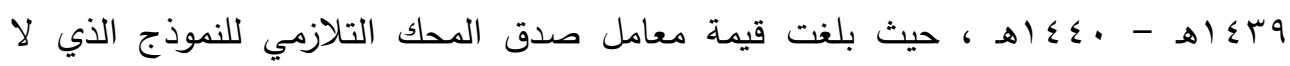

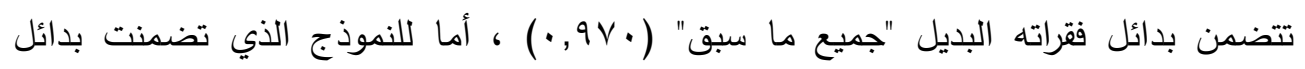

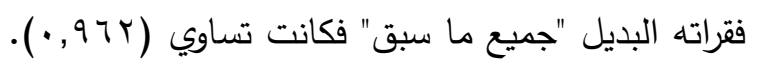
وللكثف عن دلالة الفروق تمّ استخدام الإحصائي (Fisher-Z) لفحص مدى إنى اختلاف العلاقة الارتباطية لمجموعتين مستقلتين ويبين الجدول رقم (؟) نتائج التحليل:

\begin{tabular}{|r|r|r|r|}
\hline جدول \\
\hline
\end{tabular}

من الجدول السابق يتضح أن قيمة "F" تساوي (· (1, (1) ، وتثير إلى عدم وجود فروق

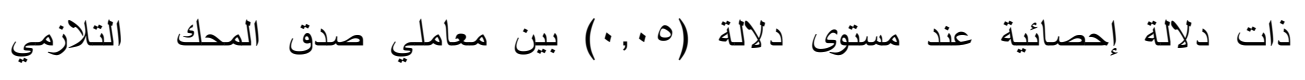
للاختبارين تعزى إلى نموذجي الاختبار مما يدل على أنه : 
لا توجد فروق ذات دلالة إحصائية بين قيم معاملات صدق المحك التلازمي في نتائج

نموذجي الاختبار التحصيلي لمادة الرياضيات من نوع الاختيار من متعدد تعزى إلى وجود

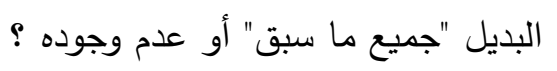

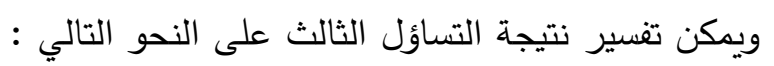

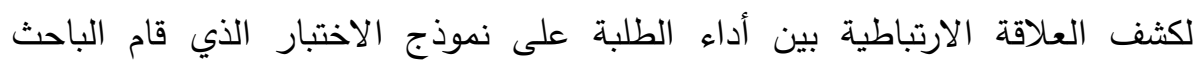

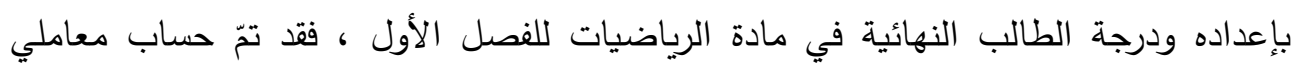

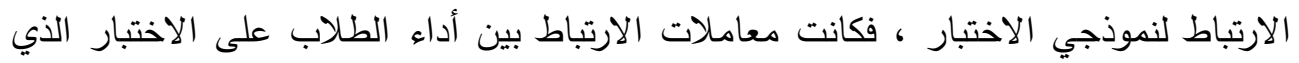

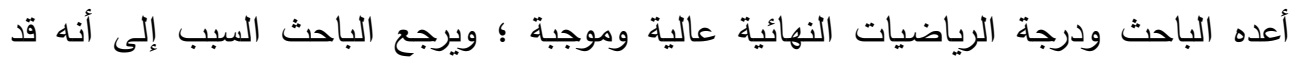

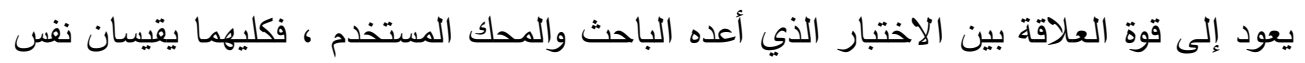
الهدف ونفس السمة لدى جميع الطلاب في نموذجي الاختبار .

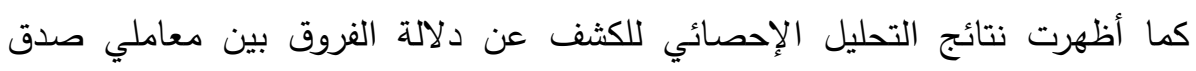
المحك التلازمي لنموذجي الاختبار (وجود البديل "جميع ما سبق" أو عدم وجوده) باستخدام

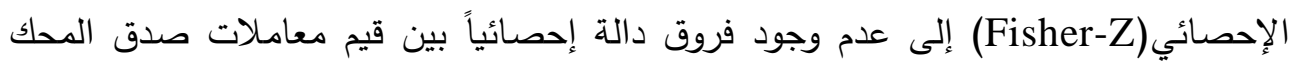

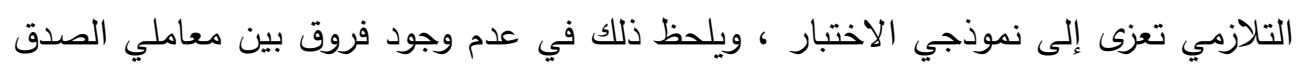

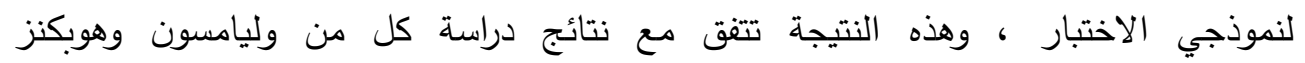

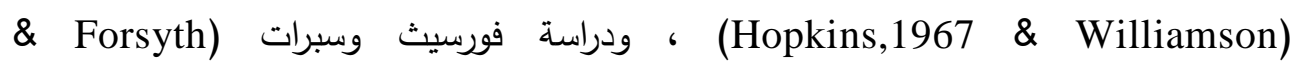

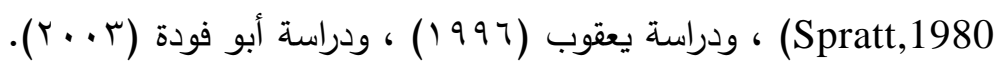

التساؤل الرابع :

هل توجد فروق ذات دلالة إحصائية بين قيم معاملات ثبات الاتساق الداخلي في نتائج نموذجي الاختبار التحصيلي لمادة الرياضيات من نوع الاختيار من متعدد تعزى إلى وجود

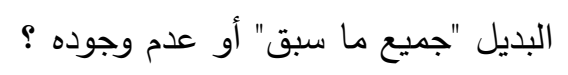
للتحقق من التساؤل الرابع تمّ حساب معامل الثبات لنموذجي اختبار الاختيار من متعدد بطريقة كودر - ريتشاردسون (KR-20) فكان للنموذج الذي لا تتضمن بدائل فقراته البديل

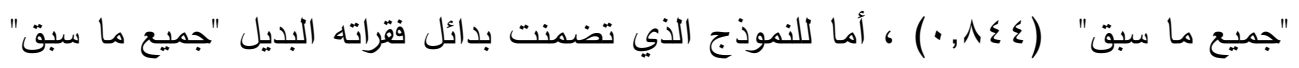

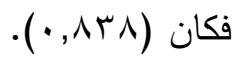


وللكثف عن دلالة الفروق تم استخدام الإحصائي (F) (1979,Feldet) للكثف عن دلالة الفروق بين معاملي الثبات لعينتين مستقلين، ويبين الجدول رقم (Y) نتائج التحليل :

\begin{tabular}{|c|c|c|c|}
\hline قيمة ( F ) الحرجة & قالمحسبة (F) & (KR-20) & النهوذج \\
\hline \multirow{2}{*}{$1, r)$} & \multirow{2}{*}{1,011} & ,,$\wedge \leqslant r$ & لا تتضمن بدائل فقراته البديل \\
\hline & & - & تتضمن بدائل فقراته البديل \\
\hline
\end{tabular}

جدول (V) : نتائج الإحصائي(F) لفحص مدى الاختلاف في معاملي ثبات الاتساق الداخلي

$$
\text { لنموذجي الاختبار }
$$

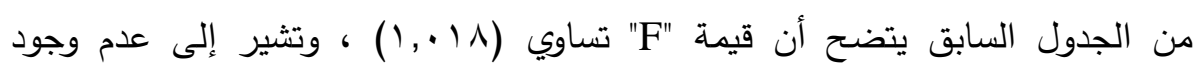
فروق دالة إحصائياً عند مستوى دلالة (ه.., ) بين معاملي ثبات الاتساق الداخلي للاختبارين تعزى إلى نموذجي الاختبار مما يدل على أنه : لا توجد فروق ذات دلالة إحصائية بين قيم معاملات ثبات الإتساق الداخلي في نتائج نموذجي الاختبار التحصيلي لمادة الرياضيات من نوع الاختيار من متعدد تعزى إلى وجود

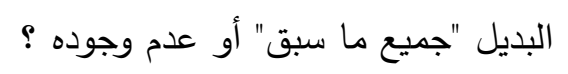

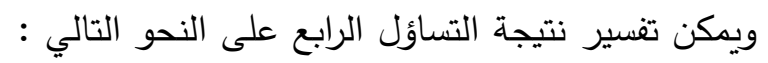
أظهرت نتائج التحليل الإحصائي للكثف عن دلئ دلالة الفروق في معاملي ثبات الاتساق

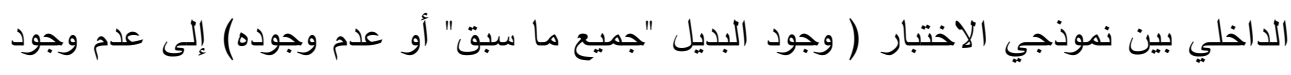
فروق جوهرية بين معاملي ثبات الاتساق الداخلي تعزى إلى نموذجي الاختبار .

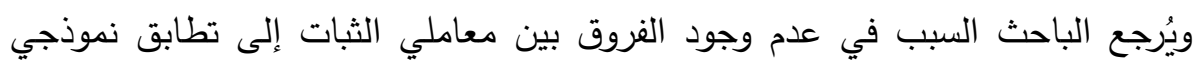

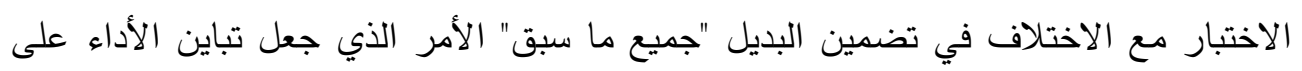
فقرات النموذجين متقارباً إلى حد كبير. كما أن الاختبارين يتمتعان بمعاملات تمييز عالية إذ أنّ الاختبار الأكثر تمييزاً أكثر

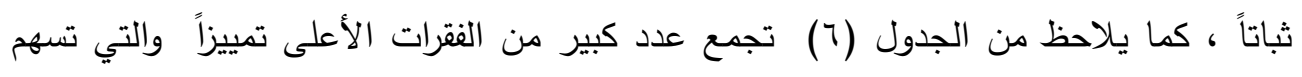
بصورة فعالة من الفقرات الأقل تمييزاً في زيادة التباين الحقيقي في نموذجي الادي الاختبار ، وهذا

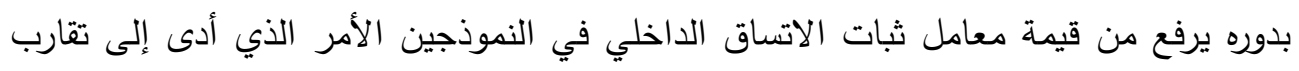

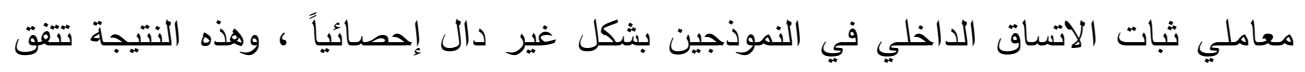

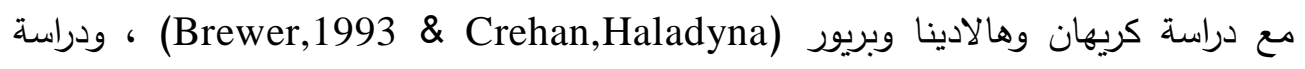


فورسيث وسبرات (Spratt,1980 \& Forsyth) ، ودراسة وليامسون وهوبكنز (Hopkins,1967 \& Williamson) (Coats, 1984 \& Oosterhof) ثانياً : التوصيات : توصي الدراسة بما يلي : تائي :

ا- استخدام الاختبار التحصيلي لدقرر الرياضيات للصف الثالث متوسط كأداة لقياس تحصيل الطلاب على مستوى إدارات التعليم بالمناطق الأخرى .

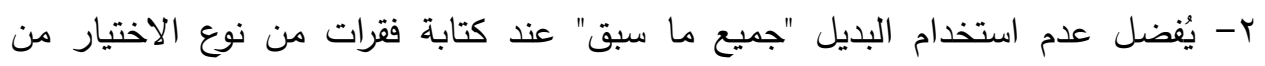

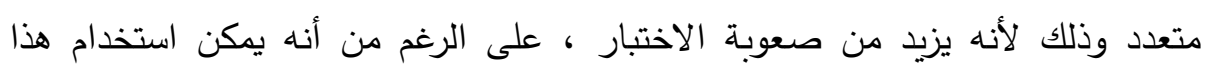

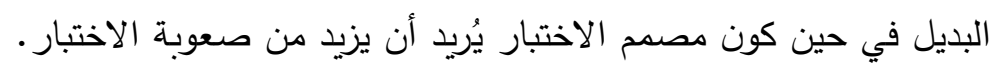

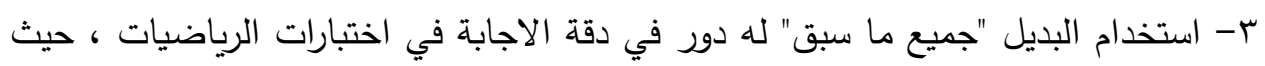
يفصل بين من يعرف الاجابة الصحيحة ومن لا يعرفها. ثالثاً : الاراسات والبحوث المقترحة : 1- بناء اختبارات تحصيلية للمقارنة بين الخصائص السيكومترية للاختبار (الصدق والثبات) وفقراته (الصعوبة والتمييز) والتي تتنـاول استخدام البديل "جميع مـا سبق" في فقرات الاختيار من متعدد لمواد أخرى ولدى مراحل تعليمية مختلفة.

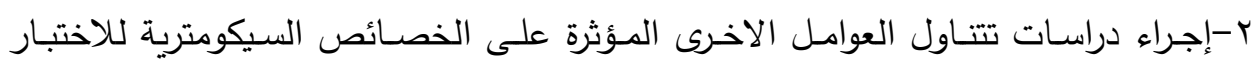

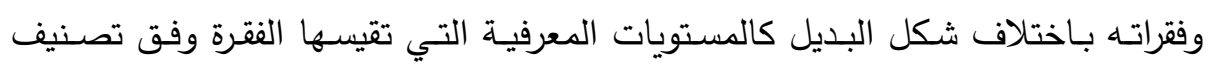
بلوم.

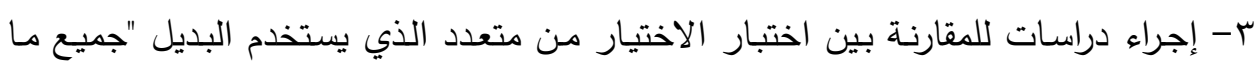
سبق" مع أشكال أخرى للاختبارات من حيث الخصائص السيكومترية للاختبار وفقراته. المراجع

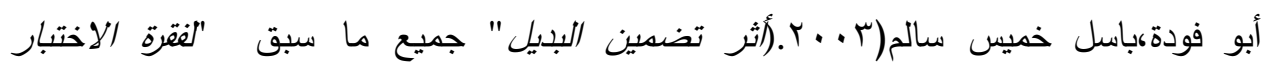

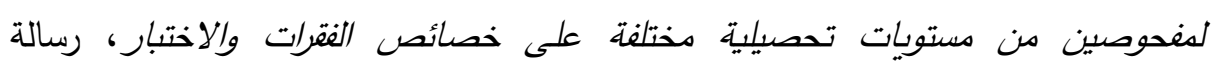
ماجستير غير منشورة، جامعة اليرموك، الأردن. 


$$
\begin{aligned}
& \text { الأمير، بندر بن زيد (T ( ب).الأخطاء الثائعة في بناء مفردات الاختيار من متعدد وتأثيرها على } \\
& \text { الخصائص السيكومترية للاختبارات التحصيلية لدى معلمات الرياضيات بالمرحلة المتوسطة بلاه } \\
& \text { بمدينة مكة، رسالة ماجستير غير منشورة، كلية التربية، جامعة ام القرى، مكة المكرمة. } \\
& \text { عودة،أحمد( • ( • (.القياس والتقويم في العملية التدريسية.عمان، اربد:دار الأمل للنشر والتوزيع. }
\end{aligned}
$$

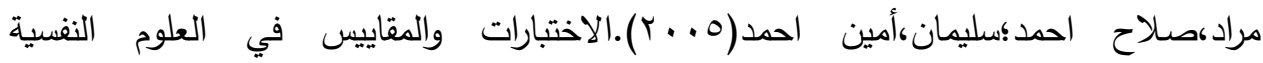

$$
\begin{aligned}
& \text { والتربوية.طץ.القاهرة:دار الكتاب الحديث. }
\end{aligned}
$$

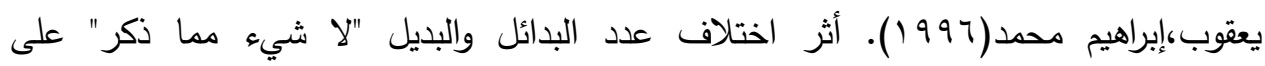

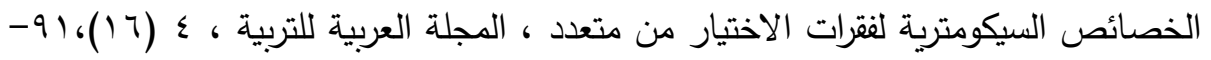

$$
\begin{aligned}
& .11 \mathrm{~V}
\end{aligned}
$$

Aiken, L. (2003 .(Psychological Testing and Assessment .Boston: Pearson Education Group.

Carey, L (1994) Measuring and Evaluating School Learning . Bouston : Allyn and Bacon .

Crehan,K.\& Haladyna,Th.(1991).The Validity of Two Items Writing Rules. Journal of experimental education.59, 183-192.

Crehan,K., \& Haladyna,Th., \& Brewer.B.(1993).Use of an Inclusive Option and the Optimal Number of Options for Multiple Choice Items .Educational and psychological measurement.53, 241-247.

Crehan,Kevin \& Others.(1989).An investigation of the Optimal Number of Options and the Inclusive "None of the These " Option.ED:314500.

Crocker, L. \& Algina, J. (1986). Introduction and Modern Test Theory. Holt Rinehart and Winston, New York: Education Group.

DiBattista, D., Sinnige-Egger, J.-A., \& Fortuna, G. (2014). The "None of the Above" Option in Multiple-Choice Testing: An Experimental Study. The Journal of Experimental Education, 82, 168-183.

Downing,S.M, (2002).Construct - Irrelevant Variance and Flawed Test Questions: Do Multiple-Choice Item Writing Principles Make Any Difference? Academic Medicine, 77(10), 103-104.

Eble,R.(1972).Essentials of Educational Measurement .New jersey: prentice-Hall,inc.

Feldet,1,.S.(1969).A Test of the Hypothesis that Cronbachs Alpha or Kuder-Richardson Coefficient twenty is the Same for Two test .Psychometrika. 34,363-373. 
Forsyth, R.A. \& Spratt, K.F. (1980). Measuring Problem Solving Ability in Mathematics with Multiple Choice Items: The Effect of Item Format on Selected Item Test Characteristics.Journal of education measurement .1, $31-43$.

Forsyth, R.A. \& Spratt, K.F. (1980). Measuring Problem Solving Ability in Mathematics with Multiple Choice Items: The Effect of Item Format on Selected Item Test Characteristics.Journal of education measurement .1, $31-43$.

Frary,R.B.(1991).The None of the Above Option: an Empirical Study. Applied measurement in education,2, 115-124.

McMillan, J. H. (2004). Classroom Assessment: principles and for Effective Instruction (3rd ed.). United states Of america.

Odegard, T. N., \& Koen, J. D. (2007). "None of the Above" as a Correct and Incorrect Alternative on a Multiple-Choice test: Implications for the Testing Effect. Memory, 15, 873-885.

Osterhof,A.C., \& Coats, P.K.(1984).Comparison of Difficulties and Reliabilities of Quantitative Word Problems in Completion MultipleChoice Items Format. Applied psychological measurement. 8,287 294.

Pachai, M. V., DiBattista, D., \& Kim, J. A. (2015). A Systematic Assessment of 'None of the Above' on Multiple Choice Tests in a First Year Psychology Classroom. The Canadian Journal for the Scholarship of Teaching and Learning, 6 (3).

Popham, W.j. (2000). Modern Educational Measuerment: Practical Guidelines for Educational Leader (3rd ed.). U.S. of Amarica.

Roid,G.,\& Haladyna,T.(1982).Atechnology for Test Item Writing.New york:Academic press, 49-55.

Tollefson,N.(1987).Acomparison of Item Difficult and Item Discrimination of Multiple - Choice Items Using The " None of the Above"and One Correct Response Options.Educational and psychological measurement.47, 377-384.

Williamson,M.L.\& Hopkins,k. D.(1967).The use of "none of these" versus homogeneous alternatives on multiple-choice tests: experimental reliability and validity comparisons.Journal of education measurements ,4, 53-58. 
